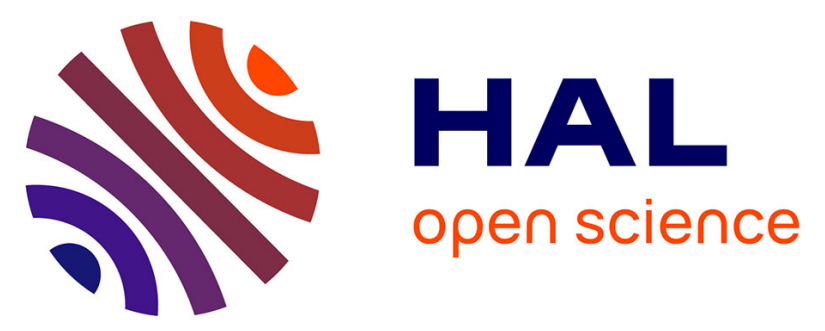

\title{
An experimental and modeling study of propene oxidation. Part 1: Speciation measurements in jetstirred and flow reactors
}

Sinéad M. Burke, Wayne Metcalfe, Olivier Herbinet, Frédérique

Battin-Leclerc, Francis M. Haas, Jeffrey Santner, Frederick L. Dryer, Henry J.

Curran

\section{To cite this version:}

Sinéad M. Burke, Wayne Metcalfe, Olivier Herbinet, Frédérique Battin-Leclerc, Francis M. Haas, et al.. An experimental and modeling study of propene oxidation. Part 1: Speciation measurements in jetstirred and flow reactors. Combustion and Flame, 2014, 161, pp.2765-2784. 10.1016/j.combustflame.2014.05.010 . hal-01069980

\section{HAL Id: hal-01069980 \\ https://hal.science/hal-01069980}

Submitted on 30 Sep 2014

HAL is a multi-disciplinary open access archive for the deposit and dissemination of scientific research documents, whether they are published or not. The documents may come from teaching and research institutions in France or abroad, or from public or private research centers.
L'archive ouverte pluridisciplinaire HAL, est destinée au dépôt et à la diffusion de documents scientifiques de niveau recherche, publiés ou non, émanant des établissements d'enseignement et de recherche français ou étrangers, des laboratoires publics ou privés. 


\title{
An experimental and modeling study of propene oxidation. Part 1: Speciation measurements in jet- stirred and flow reactors
}

\author{
Sinéad M. Burke ${ }^{a}$, Wayne Metcalfe ${ }^{a}$, Olivier Herbinet ${ }^{b}$, Frédérique Battin-Leclerc ${ }^{b}$, Francis \\ M. Haas ${ }^{c}$, Jeffrey Santner ${ }^{c}$, Frederick L. Dryer ${ }^{c}$, Henry J. Curran ${ }^{a}$ \\ ${ }^{a}$ Combustion Chemistry Centre, National University of Ireland, Galway, Ireland.

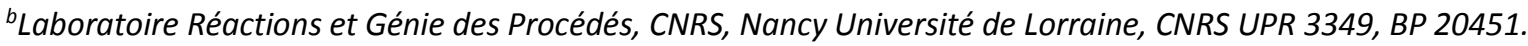 \\ ${ }^{c}$ Department of Mechanical and Aerospace Engineering, Princeton University, Princeton, NJ, United States.
}

\begin{abstract}
Propene is a significant component of Liquefied Petroleum Gas (LPG) and an intermediate in the combustion of higher order hydrocarbons. To better understand the combustion characteristics of propene, this study and its companion paper present new experimental data from jet-stirred (JSR) and flow reactors (Part I) and ignition delay time and flame speed experiments (Part II).

Species profiles from JSR experiments are presented and were obtained at near-atmospheric pressure over a temperature range of 800-1100 $\mathrm{K}$ and for equivalence ratios from $\phi=0.64$ to 2.19 . The new JSR data were obtained at lower dilution levels and temperatures than previously published. Also reported are species profiles from two high-pressure flow reactor facilities: the Princeton Variable Pressure Flow Reactor (VPFR) and the High Pressure Laminar Flow Reactor (HPLFR). The VPFR experiments were conducted at pressures of 6-12.5 atm, in the temperature range $843-1020 \mathrm{~K}$ and at equivalence ratios of $0.7-1.3$. The HPLFR experiments were conducted at $15 \mathrm{~atm}$, at a temperature of $800 \mathrm{~K}$ and at equivalence ratios of $0.35-1.25$. The flow reactor data is at higher pressures and lower temperatures than existing data in the literature.

A detailed chemical kinetic mechanism has been simultaneously developed to describe the combustion of propene under the experimental conditions described above. Important reactions highlighted via flux and sensitivity analyses include: hydrogen atom abstraction from propene by molecular oxygen, hydroxyl, and hydroperoxyl radicals; allyl-allyl radical recombination; the reaction between allyl and hydroperoxyl radicals; and the reactions of 1- and 2-propenyl radicals with molecular oxygen. The current mechanism accurately predicts the combustion characteristics of propene across the range of experimental conditions presented in this study, from jet-stirred and flow reactors and for ignition delay times and flame speed measurements presented in Part II. In comparison to a previous mechanism, AramcoMech 1.3, the current mechanism results in much improved performance, which highlights the importance of the new experimental data in constraining the important reactions.
\end{abstract}

Keywords: Propene; Jet-stirred reactor; Flow reactor; Chemical kinetics; Mechanism development 


\section{Introduction}

Propene is a key intermediate in the combustion of higher alkanes, such as propane, $n$-butane, $n$-heptane, and iso-octane, as it is a product of alkyl radical decomposition. It is a significant component of Liquefied Petroleum Gas (LPG) and due to the shale gas "revolution" there may be a surplus of LPG [1] available as an alternative energy source. Therefore, it is important to understand the combustion characteristics of propene. It may also serve as an archetypal alkene fuel. Following $\mathrm{H}$-atom abstraction from propene, a resonantly stabilized allyl radical is formed. Allylic species are implicated in the formation of aromatic and subsequent poly-aromatic hydrocarbon species [2], which are the major precursors for soot emissions. Strategies for mitigating pollutant formation in advanced combustion systems depend, in part, on understanding the oxidation chemistry of alkenes such as propene.

Despite its importance, there is a lack of experimental data available in the literature for propene at low temperatures $(600-1000 \mathrm{~K})$ and high pressures ( $\geqslant 10 \mathrm{~atm})$. There are two studies in a jet-stirred reactor (JSR) from Dagaut and co-workers [3,4] for propene oxidation. The earlier study [3] investigated propene oxidation as a function of residence time over the temperature range $900-1200 \mathrm{~K}$ in the pressure range 1-8 atm. The later atmospheric pressure study by Le Cong et al. [4] investigated the oxidation of pure propene and its oxidation in the presence of $\mathrm{CO}_{2}$ and $\mathrm{H}_{2} \mathrm{O}$ over the temperature range 950-1450 K. Previous flow reactor studies include the investigation by Davis et al. [5], who studied atmospheric pressure propene pyrolysis and oxidation ( $\phi=0.7-1.4$ ) as a function of residence time over the temperature range $1181-1210 \mathrm{~K}$.

There are several mechanisms in the literature that can be used to simulate propene combustion $[3,5-12,15]$. Westbrook and Pitz [6] developed a detailed chemical kinetic mechanism to describe the oxidation and pyrolysis of propane and propene. Dagaut et al. [3] presented a chemical kinetic reaction mechanism capable of reproducing their speciation results, with an updated version published 4 years later [15]. Their mechanism built on previous studies by Warnatz [13] and Westbrook [6] and included additional rate constants for the reactions of propene with hydroxyl and hydroperoxyl radicals from Baldwin and Walker [14].

Wilk et al. [7] developed a mechanism capable of simulating low temperature (530-740 K) static reactor data. It is one of the few mechanisms in the literature developed to simulate the low-temperature oxidation of propene. Rate constants were adopted from the literature where available. Otherwise, estimates were made by analogy to similar reactions. A region of negative temperature coefficient behavior was predicted by the model and agreed with observed experimental behavior; however, the authors stated that they "did not know if the slight deviations in the experimental data are actual indications of NTC behavior or if they are data scatter." The study by Simonyan and Mantashyan [8] also reports conflicting evidence of propene NTC behavior. The presence of NTC for propene is inconclusive and it is addressed in Part II [10] of the current work.

Tsang [9] published a review of evaluated and estimated rate constants for propene unimolecular decomposition reactions, $\mathrm{H}$-atom abstraction reactions, and reactions of the allyl radicals formed therein. Rate constant recommendations originated from experimental measurements where available or were otherwise estimated.

More recently, Davis et al. [5] presented a chemical kinetic mechanism to describe the high-temperature kinetics of propane, propene, allene, and propyne. The mechanism included rate constants adopted from the literature and calculated via ab initio quantum mechanical and Rice-Ramsperger-Kassel-Marcus (RRKM) analyses. It was validated against the flow reactor and flame speed data presented in their study, in addition to flame speed targets from the literature.

The propene oxidation mechanism presented by Heyberger et al. [11] was generated using the EXGAS code. The mechanism was validated against speciation data from a JSR and low-temperature static reactor data. 
Braun-Unkhoff et al. [12] presented a propene sub-mechanism validated against laminar flame speed and ignition delay time data. Rate constants for both propene pyrolysis and oxidation sub-mechanisms were adopted from the literature $[5,9,16-18]$.

\section{Experimental methods}

Table 1 compares the experimental conditions investigated during this study to those of previous ones. The present JSR data were obtained under similar conditions to previous studies from Dagaut and co-workers [3] and [4]. However, the mixtures investigated in this study used a higher concentration of reactants (for example, we used $\approx 1.62 \% \mathrm{C} 3 \mathrm{H} 6$ while Dagaut and co-workers $[3,4]$ used $0.15 \% \mathrm{C} 3 \mathrm{H} 6$ for the same equivalence ratio). The more concentrated mixtures facilitated measurement of reactivity in a lower temperature range compared to the previous studies. Profiles for additional species such as allene, propyne, butene, acrolein, and 1,5-hexadiene were also reported. These species proved useful for mechanism development; for example, the detection of butene and 1,5-hexadiene indicated the importance of certain radical-radical recombination reactions. New data from the flow reactors were obtained at lower temperatures and higher pressures than the previous studies. The experimental data are compared with predictions of a chemical kinetic mechanism and all simulations presented in this study were performed using the CHEMKIN-PRO [19] suite of programs.

Table 1. Jet-stirred reactor and flow reactor data for propene oxidation.

\begin{tabular}{|c|c|c|c|c|c|}
\hline Reactor & $T(\mathrm{~K})$ & $p$ (atm) & $\varphi$ & Dilution & Ref. \\
\hline \multicolumn{6}{|c|}{ Data for propene oxidation available in the literature } \\
\hline Static & $580-715$ & 0.79 & $0.8-2.0$ & "in air" & [7] \\
\hline JSR & $900-1200$ & $1-8$ & $0.15-4.0$ & $>95 \% \mathrm{~N}_{2}$ & [3] \\
\hline JSR & $950-1200$ & 1.0 & $0.5-2.0$ & $>95 \% \mathrm{~N}_{2}$ & [4] \\
\hline FR & $950-1200$ & 1.0 & Pyrolysis & $>95 \% \mathrm{~N}_{2}$ & [5] \\
\hline$F R$ & $1180-1210$ & 1.0 & $0.5-2.0$ & $>95 \% \mathrm{~N}_{2}$ & [5] \\
\hline
\end{tabular}

\begin{tabular}{lcccc}
\multicolumn{5}{c}{ Data for propene oxidation obtained in this study } \\
JSR & $800-1100$ & 1.05 & $0.64-2.19$ & $>87-95 \% \mathrm{He}$ \\
FR & 800 & 15.0 & $0.35-1.25$ & $>90 \% \mathrm{~N}_{2}$ \\
FR & $840-1020$ & $6.0-12.5$ & $0.7-1.31$ & $>97 \% \mathrm{~N}_{2}$ \\
\hline
\end{tabular}

\subsection{Jet-stirred reactor}

Experiments were performed in a spherical fused silica jet-stirred reactor operated at constant temperature and pressure located at the Laboratoire Réactions et Génie des Procédés (LRGP) at the University of Lorraine in Nancy, France. The experimental apparatus has been described previously $[20,21]$ and only the main features are discussed here. Stirring is achieved by turbulent jets flowing through an injection cross located at the center of the sphere. The rapid mixing achieves spatial temperature and concentration homogeneity within the reactor when it is operated at a steady state. The internal volume of the reactor is $92 \mathrm{~cm} 3$ and it has been designed to operate with residence times of 0.5-5.0 s [22]. In order to avoid temperature gradients within the reactor it is preceded by an annular pre-heater, where the temperature of the vapor mixture is increased to the temperature of the reactor before entering it. The residence time in the preheater is long enough to heat the gas to the reaction temperature due to the annular geometry. The residence time of the 
gas inside the pre-heater is $1 \%$ of the total residence time in the reactor. Heating is achieved with independent 'Thermocoax' resistance heaters coiled around the different zones of the experimental set up. The reaction temperature is measured using a type $\mathrm{K}$ thermocouple. The thermocouple is located inside the intra-annular space of the pre-heating zone, the extremity of which is on the level of the injection cross. The uncertainty in the temperature measurement is $\pm 5 \mathrm{~K}$.

Reaction products were analyzed using online gas chromatography. In total, three gas chromatographs were used to quantify a wide range of products. Light species such as oxygen, carbon monoxide, carbon dioxide, and $\mathrm{C}_{1}-\mathrm{C}_{2}$ hydrocarbons were analyzed using a gas chromatograph fitted with a sampling valve, a carbosphere packed column, and two detectors: a thermal conductivity detector (TCD) for oxygen atom containing species and a flame ionization detector (FID) for hydrocarbons. Helium was used as a carrier gas in the GC as it was also used as a diluent gas in the experiments. A second gas chromatograph was used for the quantification of $C_{1}-C_{6}$ hydrocarbons and was fitted with a sampling valve, a capillary Plot $Q$ column, and an FID, with the same carrier gas. Despite the use of these two gas chromatographs, important species such as formaldehyde and water could not be quantified. The calibration of the gas chromatographs was performed using gaseous standards provided by Messer and Air Liquide. For species not directly calibrated from standards, the effective carbon number method was used to calculate the calibration coefficient [23]. The uncertainty in the mole fraction was estimated at $\pm 5 \%$ (less for species directly calibrated). The detection limit was about $1 \mathrm{ppm}$ for hydrocarbons detected with the FID. The detection limit in the measurements was 10 and $100 \mathrm{ppm}$ for $\mathrm{CO}$ and $\mathrm{CO}_{2}$, respectively (with the TCD). Species identification was performed with a third gas chromatograph coupled to a mass spectrometer. The mass spectra of most species were included in the NIST08 spectra database [24]. The residence time for each mixture was $2.0 \mathrm{~s}$ and the pressure was fixed to $106.7 \mathrm{kPa}$ (800 Torr). The exact compositions of the mixtures studied are included in Table 2. Concentration profiles of stable species such as oxygen, carbon monoxide, carbon dioxide, methane, ethylene, acetylene, ethane, propene, allene, propyne, acetaldehyde, butene isomers, 1,3-butadiene, methyl oxirane, acrolein, propanal, acetone, benzene, 1,5hexadiene were measured during the experiments.

Table 2. Experimental conditions for the JSR. $\tau=2.0 \mathrm{~s}$ and $\mathrm{p}=1.05 \mathrm{~atm}$.

\begin{tabular}{cccc}
\hline $\boldsymbol{\varphi}$ & $\mathrm{C}_{3} \mathrm{H}_{6}(\%)$ & $\mathbf{O}_{2}(\%)$ & He (\%) \\
\hline 0.64 & 1.65 & 11.60 & 86.75 \\
1.10 & 1.62 & 6.81 & 91.57 \\
1.68 & 1.68 & 4.50 & 93.82 \\
2.19 & 1.64 & 3.38 & 95.28 \\
\hline
\end{tabular}

\subsubsection{Jet-stirred reactor simulation}

The CHEMKIN-PRO steady state solver was used for simulations and included isothermal, isobaric assumptions.

\subsection{Flow reactor}

Experiments were conducted in two flow reactors at Princeton University, the Variable Pressure Flow Reactor (VPFR) and the High Pressure Laminar Flow Reactor (HPLFR). 


\subsubsection{Flow reactor simulation}

Simulations of VPFR experiments were performed assuming a 0-D system with isobaric and adiabatic approximations. In order to compare model predictions to time history measurements performed in the Princeton VPFR, the simulations are subject to a time-shifting procedure [26]. The time-shifting technique has been thoroughly discussed by Zhao et al. [27]. The HPLFR is simulated using an isothermal assumption and is also subject to a time-shifting procedure, which is further discussed below.

\subsubsection{Princeton Variable Pressure Flow Reactor (VPFR)}

The design, instrumentation and experimental methodology of this apparatus have been discussed in detail previously [27-29] and are therefore only briefly reviewed here. The carrier gas $\left(\mathrm{N}_{2}\right)$ is heated and mixed with oxygen as it enters the reactor tube. The carrier gas/oxygen mixture flows around a baffle plate into a gap serving as the entrance to a diffuser. The remaining reactant (fuel) is diluted with N2 and injected radially outward into this gap where it rapidly mixes with the carrier gas and oxygen, establishing the initial reaction temperature for the experiment. The reacting mixture exits the diffuser into the test section. Near the exit of the test section, a sampling probe is positioned on the reactor centerline to continuously extract and convectively quench a small percentage of the flow. At the same axial location, the local reaction gas temperature is measured with a silica-coated R-type thermocouple. The sample gas flows via heated Teflon lines to analytical equipment that includes a Fourier transform infrared spectrometer (FTIR), an electrochemical $\mathrm{O}_{2}$ analyzer, and a pair of non-dispersive infrared analyzers for $\mathrm{CO}$ and $\mathrm{CO}_{2}$. Small volumes of the sample flow can also be stored in heated multi-port sample storage valve systems that can be transferred to a $\mathrm{GC}$ for off-line analysis. $\mathrm{C}_{3} \mathrm{H}_{6}, \mathrm{H}_{2} \mathrm{O}, \mathrm{CH}_{2} \mathrm{O}$ and $\mathrm{C}_{2} \mathrm{H}_{2}$ were measured on-line using FTIR spectrometry. $\mathrm{C}_{2} \mathrm{H}_{4}$, $\mathrm{CH}_{4}, \mathrm{C}_{2} \mathrm{H}_{6}$, iso-butene and 1,3-butadiene were measured using sample storage and subsequent off-line $\mathrm{GC}$ analysis. Species profiles for $\mathrm{O}_{2}, \mathrm{CO}, \mathrm{CO}_{2}, \mathrm{H}_{2}, \mathrm{CH}_{2} \mathrm{O}, \mathrm{CH}_{4}, \mathrm{C}_{2} \mathrm{H}_{4}$ and $\mathrm{C}_{3} \mathrm{H}_{6}$ are reported in Section 4.2.1.

Table 3 contains selected mixtures studied in the VPFR while Table 4 provides a summary of the conditions studied in the HPLFR; further experiments are included as Supplementary Material.

Table 3. Experimental conditions studied in the VPFR. ${ }^{a}$

\begin{tabular}{cccccc}
\hline $\boldsymbol{p}$ (atm) & $\boldsymbol{T}(\mathrm{K})$ & $\boldsymbol{\varphi}$ & $\mathrm{C}_{3} \mathrm{H}_{6}(\%)$ & $\mathbf{O}_{2}$ (\%) & $\mathbf{N}_{\mathbf{2}}$ (\%) \\
\hline 8.0 & 955 & 0.94 & 0.31 & 1.49 & 98.20 \\
10.0 & 942 & 1.37 & 0.34 & 1.10 & 98.56 \\
12.5 & 843 & 0.71 & 0.33 & 2.10 & 97.57 \\
\hline
\end{tabular}

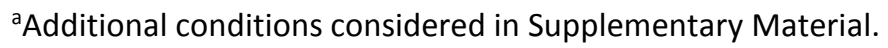

Table 4. Experimental conditions studied in the HPLFR, $T=800 \mathrm{~K}$ and $p=15.0 \mathrm{~atm}$.

\begin{tabular}{cccc}
\hline $\boldsymbol{\varphi}$ & $\mathrm{C}_{\mathbf{3}} \mathrm{H}_{\mathbf{6}}$ & $\mathbf{O}_{2}$ & $\mathbf{N}_{\mathbf{2}}$ \\
\hline 0.35 & 0.40 & 5.14 & 94.45 \\
0.50 & 0.45 & 4.05 & 95.50 \\
1.00 & 0.50 & 2.50 & 97.25 \\
1.25 & 0.62 & 2.25 & 97.13 \\
\hline
\end{tabular}




\subsubsection{High Pressure Laminar Flow Reactor (HPLFR)}

The HPLFR is a new reactor facility developed to measure both fundamental chemical kinetic rate coefficients as well as systems-type reaction features for species of interest to combustion and gas phase reaction kinetics. This facility is described in detail in the thesis of Haas [30], which also describes its favorable validation performance in measuring relatively well established rate coefficients for the reactions $\dot{\mathrm{H}}+\mathrm{O}_{2}(+\mathrm{M}) \rightarrow \mathrm{HO}_{2}(+\mathrm{M})$ (where $\mathrm{M}=\mathrm{N}_{2}$ and $\mathrm{Ar}$ ) and $\dot{\mathrm{H}}+\mathrm{NO}_{2} \rightarrow \mathrm{NO}+\dot{\mathrm{O}} \mathrm{H}$. Accordingly, only a brief description of the system is presented below.

The HPLFR essentially consists of a $38 \mathrm{~mm}$ OD stainless steel pressure shell enclosed by a PID-thermostatted three-zone tube furnace. This pressure shell itself encloses one of several coaxial reactor duct designs. In the present experiments, the quartz test section of the duct is of cylindrical geometry and has an internal diameter of $10 \mathrm{~mm}$. The duct is fed by a steady flow of premixed, preheated gaseous reactants supplied from calibrated mass flow controllers. Under conditions favoring reaction, premixed gas feed converts into products as it travels along the duct and subsequently exhausts from the reactor. A back pressure regulator on the exhaust line controls the pressure both inside the duct and in the annular space between the duct and the pressure shell. This feature automatically maintains pressure equilibrium across the fragile quartz duct wall. The reactor facility accommodates relatively high pressures (30 atm) and temperatures ranging from approximately 500$1000 \mathrm{~K}$.

A small fraction of the reacting flow in the duct is extracted from the test section using a hot water-cooled, convection quench probe with integrated thermocouple. This continuous, quenched sample flow passes through heated Teflon transfer lines $\left(100{ }^{\circ} \mathrm{C}\right)$ to a pressure-regulated online Inficon 3000 micro gas chromatograph, which permits identification and quantification of stable species of interest. Stable species mole fractions are determined from chromatogram area responses and retention times measured from dilutions of calibration standards. A screw drive translates the probe axially through the duct, enabling sample collection at different axial locations along the length of the test section.

The steady laminar reacting flow field in the HPLFR (or any hydrodynamically similar facility) may support both axial and radial gradients in velocity, species mole fraction, and temperature. However, modeling [30] of the specific axisymmetric reacting flow conditions describing the present experiments shows that the experiments are reasonably well characterized by simple steady 1-D axial plug flow, particularly for low fuel conversion where transport gradients are small. Diagnostic experiments described in [30], as well as demonstrated HPLFR validation against literature rate coefficients for $\dot{\mathrm{H}}+\mathrm{O}_{2}(+\mathrm{M}) \rightarrow \mathrm{HO}_{2}(+\mathrm{M})$ and $\dot{\mathrm{H}}+\mathrm{NO}_{2} \rightarrow \mathrm{NO}+\dot{\mathrm{O}} \mathrm{H}$ suggest negligible influence of wall reactions on the quartz duct for species spanning a broad spectrum of reactivities (i.e., $\dot{H}$ and $\dot{\mathrm{OH}}, \mathrm{HO} 2$, NOx, and stable reactants/products). Consequently, a mean velocity-axial displacement relationship gives the effective $0-D$ homogeneous chemistry residence time in the test section, subject to additional treatment discussed in Section 4.2. It is important to note that this simplification of the complex interaction of the chemical source term with thermal and species diffusion and the laminar flow-field applies only for specific experimental conditions, and does not generalize to any conditions beyond those reported here.

Experimental composition measurements of the reacting flow were obtained by convection quenched sampling at discrete axial locations, followed by micro $\mathrm{GC}$ analysis of the flowing sample gases. Species profiles were reported for stable species including $\mathrm{C}_{3} \mathrm{H}_{6}, \mathrm{O}_{2}, \mathrm{CO}, \mathrm{CO}_{2}$, and $\mathrm{H}_{2} \mathrm{O}$. The micro $\mathrm{GC}$ was calibrated to measure $\mathrm{H}_{2}, \mathrm{CH}_{4}, \mathrm{C}_{2} \mathrm{H}_{6}, \mathrm{C}_{3} \mathrm{H}_{4}$-a (allene), and $\mathrm{C}_{3} \mathrm{H}_{4}-\mathrm{p}$ (propyne) in addition to the species reported below. Mole fractions of these additional species were below detection/quantification limits of tens of ppm for all experiments; an observation which is itself mechanistically constraining. The retention time for $\mathrm{CH}_{2} \mathrm{O}$ was identified using formalin solution, but the mole fraction could not be accurately, independently quantified. For the $\phi=0.35$ and 0.5 experiments, $\mathrm{H}_{2} \mathrm{O}$ and $\mathrm{CH}_{2} \mathrm{O}$ measurements have been excluded as a result of sample condensation 
observed during the experiments. Effects of this condensation on the mole fractions of other reported species was found to be negligible.

\section{Chemical kinetic mechanism development}

The foundation of the detailed kinetic mechanism presented in this study is based on recent publications. The $\mathrm{H}_{2} / \mathrm{O}_{2}$ sub-mechanism is adopted from the study of Kéromnès et al. [31] and the $\mathrm{C}_{1} / \mathrm{C}_{2}$ sub-mechanism (AramcoMech 1.3) adopted from the recent publications of Metcalfe and co-workers [32-36]. AramcoMech 1.3 included rate constants for $C_{3}$ and $C_{4}$ species such as propene, allene, propyne, and 1,3-butadiene, adopted from the study by Laskin et al. [41], as well as rate constants for the butane isomers from the studies of Healy and co-workers [37-40]. Rate constants for the aromatic sub-mechanism were included from the toluene study by Metcalfe et al. [42]. However, despite AramcoMech 1.3 [32] containing mechanistic structure, thermochemistry, and rate parameters for reactions of larger hydrocarbon species and radicals, the model was not extensively validated for species larger than $C_{2}$. We aim to improve the predictive power of the mechanism for the range of experiments presented herein. Changes to both kinetic and thermochemical data have taken place and these changes are discussed in detail below.

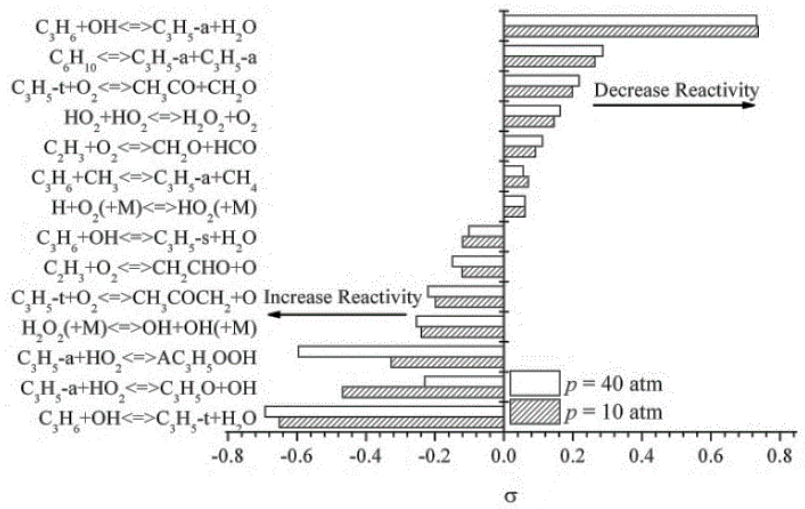

(a) Brute force sensitivity analysis of $\mathrm{C}_{3} \mathrm{H}_{6} /$ air IDTs. $\phi=1.0, \mathrm{~T}=950 \mathrm{~K}$.

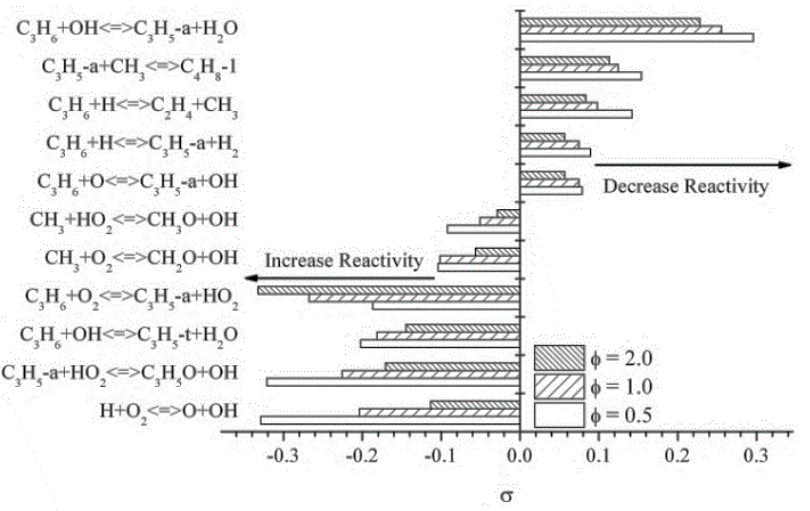

(b) Brute force sensitivity analysis of $\mathrm{C}_{3} \mathrm{H}_{6} /$ air IDTs. $p=10 \mathrm{~atm}, \mathrm{~T}=1250 \mathrm{~K}$.

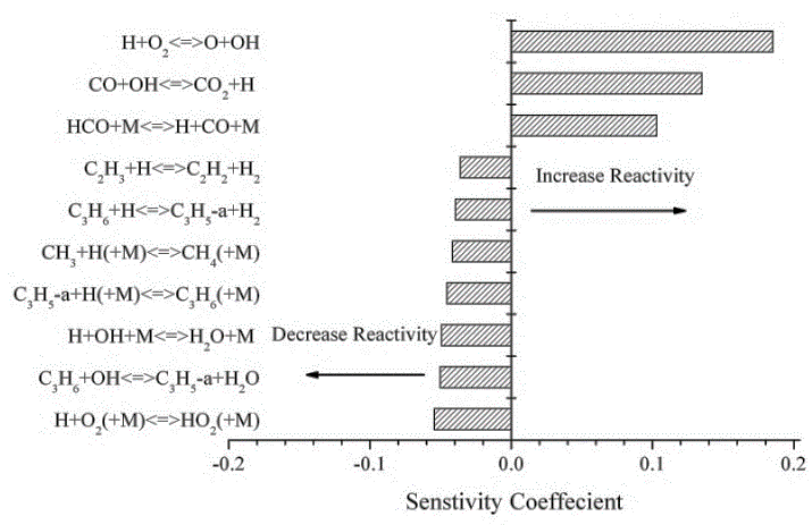

(c) Flame speed sensitivity analysis of $\mathrm{C}_{3} \mathrm{H}_{6} /$ air laminar flame at $1 \mathrm{~atm}$.

Figure 1. Important reactions for propene oxidation highlighted by sensitivity analyses carried out during the course of this study. 
During its development, the mechanism was validated against experimental targets at a variety of experimental conditions. The speciation measurements presented in this study and ignition and flame speed data presented in Part II [10] were all tested concurrently. Important reactions for propene oxidation in the JSR and flow reactor were highlighted by flux analyses as shown in Figures 18 and 26. In order to highlight the important reactions for propene oxidation over the entire range of conditions studied, sensitivity analyses for reflected shock ignition delay times (IDTs) and laminar flame speed data [10] are included in Figure 1.

The choice of rate constants for many of the important reactions highlighted in Figure 1 are discussed and explained below. The Arrhenius coefficients for all of the important reactions are in a table provided as Supplementary Material. The complete kinetic mechanism, thermochemistry and transport files are available to download at http://c3.nuigalway.i.e./mechanisms.html.

The mechanism developed in this work results in improved performance against a variety of experimental data. The most significant improvement can be seen when compared against data at lower temperatures and at higher pressures, where the new experimental data presented in this study from shock tubes, RCMs, JSRs, flow reactors and flame speeds have provided important validation targets. The performance of the mechanism presented in this study is compared with the performance of selected mechanisms available in the literature $[5,12,32]$ provided as Supplementary Material.

\section{1. $\mathrm{C}_{3} \mathrm{H}_{6}(+\mathrm{M}) \leftrightarrow$ Products}

$$
\begin{aligned}
& \text { - } \dot{\mathrm{C}}_{3} \mathrm{H}_{5}-\mathrm{a}+\dot{\mathrm{H}}(+\mathrm{M}) \leftrightarrow \mathrm{C}_{3} \mathrm{H}_{6}(+\mathrm{M}) \\
& \text { - } \dot{\mathrm{C}}_{2} \mathrm{H}_{3}+\dot{\mathrm{C}} \mathrm{H}_{3}(+\mathrm{M}) \leftrightarrow \mathrm{C}_{3} \mathrm{H}_{6}(+\mathrm{M})
\end{aligned}
$$

Propene/air laminar flame speeds are sensitive to propene decomposition to allyl radical and a hydrogen atom, Figure 1 (c). This rate constant, which we describe in the recombination direction, has been adopted from the study by Tsang [9]. However, in order to improve agreement with flame speed measurements presented in Part II [10], the rate constant for the recombination of allyl radical and atomic hydrogen was reduced by a factor of two, this is within the stated uncertainty [9]. Figure 2 shows that reducing the rate of this reaction increased the flame speed by approximately $2 \mathrm{~cm} \mathrm{~s}^{-1}$. This reduction had little or no effect on mechanism performance against other experimental targets. Flames are less sensitive to the channel producing vinyl and methyl radicals, and this rate coefficient is adopted unchanged from the study by Tsang.

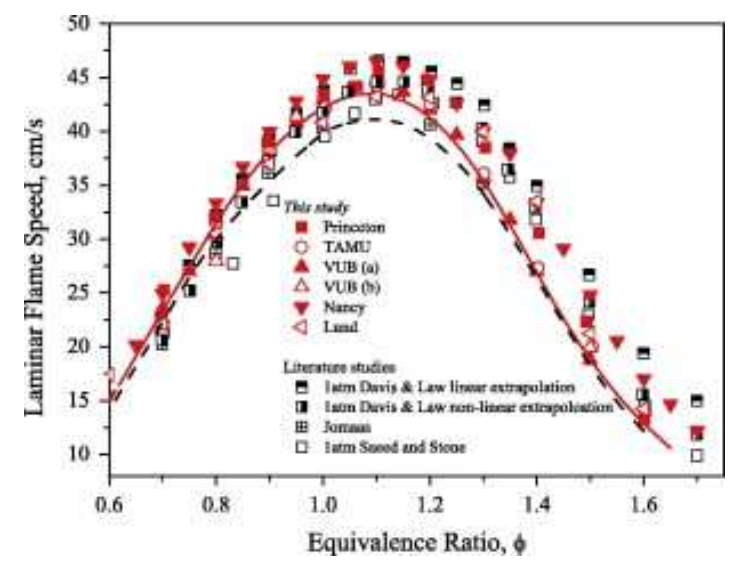

Figure 2. Effect of changing the $\dot{\mathrm{C}}_{3} \mathrm{H}_{5}-\mathrm{a}+\dot{\mathrm{H}}(+\mathrm{M}) \leftrightarrow$ $\mathrm{C}_{3} \mathrm{H}_{6}(+\mathrm{M})$ rate constant on predictions of 1 atm flame speeds (red symbols new data [10]). - - - Tsang [9], ___ [9] reduced by a factor of two. Literature study references in [10]. ([25,43,62].) (For interpretation of the references to color in this figure legend, the reader is referred to the web version of this article.) 


\section{2. $\mathrm{C}_{3} \mathrm{H}_{6}+\dot{\mathrm{R}} \leftrightarrow$ Products}

Propene can undergo hydrogen atom abstraction from three sites: the methyl site forming the resonantly stabilized allyl radical $\left(\dot{\mathrm{C}}_{3} \mathrm{H}_{5}-\mathrm{a}\right)$, the other terminal carbon resulting in the formation of a vinylic radical propen-1-yl $\left(\dot{\mathrm{C}}_{3} \mathrm{H}_{5}-\mathrm{s}\right)$; and the central carbon to give propen-2-yl $\left(\dot{\mathrm{C}}_{3} \mathrm{H}_{5}-\mathrm{t}\right)$. Hydrogen atom abstraction resulting in the formation of the allyl radical is generally dominant as the methylic $\mathrm{C}-\mathrm{H}$ bonds are the weakest $\mathrm{C}-\mathrm{H}$ bonds in propene. Abstraction reactions by various radicals are discussed in the following subsections.

\subsection{1. $\mathrm{C}_{3} \mathrm{H}_{6}+\dot{\mathrm{H}} \leftrightarrow$ Products}

Sensitivity analyses, Figure 1(b), and flux analyses, Figures 18 and 26, have identified the importance of reactions between propene and atomic hydrogen. At high and intermediate temperatures ( $>1200 \mathrm{~K}$ ) hydrogen atom addition to propene acts to inhibit reactivity, as it competes with the main chain branching and reactivity promoting reaction, $\dot{\mathrm{H}}+\mathrm{O}_{2} \leftrightarrow \mathrm{O}^{\prime \prime}+\dot{\mathrm{O}} \mathrm{H}$. As temperatures decrease $(<800 \mathrm{~K}), \mathrm{C}_{3} \mathrm{H}_{6}+\dot{\mathrm{H}}$ reactions promote reactivity. Both $n$ - and iso-propyl radicals undergo low-temperature chemistry reactions via reaction with molecular oxygen to form $\mathrm{RO}_{2}$ radicals, which after a series of isomerization reactions and further molecular oxygen addition reactions, eventually lead to the formation of several radicals, thereby promoting reactivity.

Previously [32], an estimated high-pressure limit rate constant for the alkyl radical decomposition channels from Curran [44] and an estimated rate constant from the study of Tsang [9] for the ethylene and methyl radical channel were included in the mechanism. In this study, the rate constants for hydrogen atom addition to and abstraction from propene have been adopted from the recent theoretical study of Miller and Klippenstein [45]; they used CCSD(T)/ccpVTZ (for the non-abstraction reactions) and the MP2/6-311++G(d,p) methods (for the abstraction reactions).

Miller and Klippenstein provided pressure dependent rate constants for the reactions that occur on the $\dot{\mathrm{C}}_{3} \mathrm{H}_{7}$ potential energy surface. They stated that the dominant product sets for $\mathrm{C}_{3} \mathrm{H}_{6}+\dot{\mathrm{H}}$ are the formation of iso- $\dot{\mathrm{C}}_{3} \mathrm{H}_{7}$ and $n-\dot{\mathrm{C}}_{3} \mathrm{H}_{7}$ radicals, and $\mathrm{C}_{2} \mathrm{H}_{4}+\dot{\mathrm{C}}_{3}$. In addition to the reaction between methyl radical and ethylene that results in the formation of $n-\dot{C}_{3} \mathrm{H}_{7}$ radicals, Miller and Klippenstein provided rate constants for the abstraction channel that results in the formation of a vinyl radical and methane. The total addition rate constant adopted in this study is larger than the previous total rate constant, but its inclusion had only a small effect on the mechanism performance for propene. Inclusion of these rate constants has a significant effect on the performance of the mechanism against ethylene targets, as shown in Supplementary Material.

\subsection{2. $\mathrm{C}_{3} \mathrm{H}_{6}+\dot{\mathrm{C}} \mathrm{H}_{3} \leftrightarrow$ Products}

Methyl radical can abstract a hydrogen atom from propene from any of the three sites, however, only the channel producing methane and an allyl radical was observed to be competitive. This reaction is predicted to be a significant source of methane detected in the JSR. The recommendation in this study is an estimated rate constant from Tsang [9].

We did not observe sensitivity to methyl radical addition to propene to form $\dot{\mathrm{C}}_{4} \mathrm{H}_{9}$ radicals during this study. However, rate constants for methyl radical addition to propene resulting in the formation of iso- and 2-butyl radicals are included from Curran [44]. 


\subsection{3. $\mathrm{C}_{3} \mathrm{H}_{6}+\mathrm{O} \mathrm{H} \leftrightarrow$ Products}

\subsubsection{Abstraction by $\mathrm{OH}$}

The hydroxyl radical is a dominant reactive radical in combustion processes. It is highly reactive, which is due in part to the exothermicity of water formation which is relatively large at $-57.80 \mathrm{kcal} \mathrm{mol}^{-1}$. Ignition delay times are highly sensitive to the branching ratio between the three abstraction channels, as seen in Figure 1(a). The allyl radical producing channel is the most inhibiting of the three, it results in the consumption a highly reactive hydroxyl radical and the formation of a far less reactive resonantly stabilized allyl radical. The $\dot{\mathrm{C}}_{3} \mathrm{H}_{5}$-a radical can readily undergo radical-radical recombination with itself or with methyl radicals via chain terminating reactions which inhibit reactivity. The channels forming $\dot{\mathrm{C}}_{3} \mathrm{H}_{5}$-t and $\dot{\mathrm{C}}_{3} \mathrm{H}_{5}$-s radicals promote reactivity. These radicals react with molecular oxygen via chain branching pathways.

Rate constants for the reactions of propene with hydroxyl radicals have been adopted from the experimental study of Vasu et al. [46], who measured the rate constant in a shock tube using laser absorption. Zádor et al. [47] investigated these reactions theoretically employing RQCISD(T)/ccpV $\infty Z / / B 3 L Y P / 6-311++G(d, p)$ quantum chemical calculations. The total rate constants recommended in these two recent studies are in good agreement as shown in Figure 3; up to $1500 \mathrm{~K}$ they agree within $10 \%$ and are within $20 \%$ of each other between 1500 and up to $2000 \mathrm{~K}$. Unlike the study of Vasu et al., the theoretical study of Zádor et al. provided a branching ratio which we have adopted.

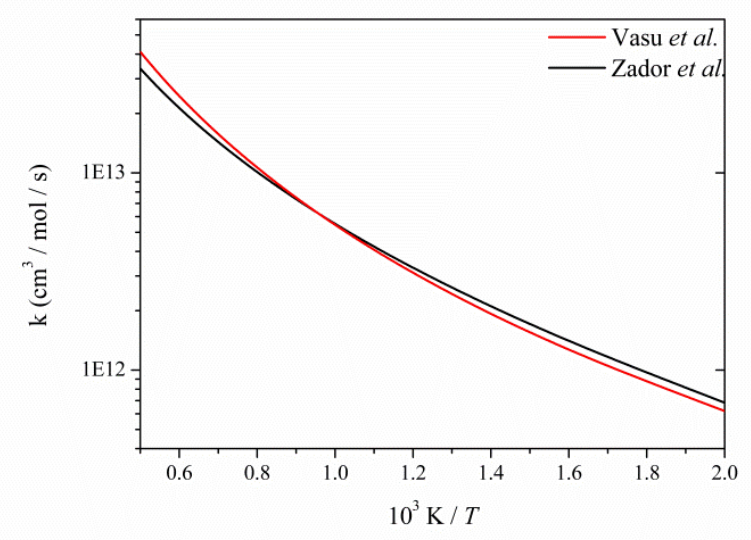

Figure 3. Total $\mathrm{C}_{3} \mathrm{H}_{6}+\mathrm{O} H$ abstraction rate constant, Vasu et al. [46] and Zádor et al. [47].

\subsection{4. $\mathrm{OH}$ addition to $\mathrm{C}_{3} \mathrm{H}_{6}$}

- $\mathrm{C}_{3} \mathrm{H}_{6}+\mathrm{O} H \leftrightarrow \dot{\mathrm{C}}_{3} \mathrm{H}_{6} \mathrm{OH} 1-2$

- $\mathrm{C}_{3} \mathrm{H}_{6}+\mathrm{O} \mathrm{H} \leftrightarrow \dot{\mathrm{C}}_{3} \mathrm{H}_{6} \mathrm{OH} 2-1$

- $\mathrm{C}_{3} \mathrm{H}_{6}+\dot{\mathrm{OH}} \leftrightarrow \mathrm{C}_{3} \mathrm{H}_{5} \mathrm{OH}+\dot{\mathrm{H}}$

- $\mathrm{C}_{3} \mathrm{H}_{6}+\dot{\mathrm{O}} \mathrm{H} \leftrightarrow \mathrm{C}_{2} \mathrm{H}_{3} \mathrm{OH}+\dot{\mathrm{C}} \mathrm{H}_{3}$

- $\mathrm{C}_{3} \mathrm{H}_{6}+\dot{\mathrm{OH}} \leftrightarrow \mathrm{iC}_{3} \mathrm{H}_{5} \mathrm{OH}+\dot{\mathrm{H}}$

- $\mathrm{C}_{3} \mathrm{H}_{6}+\mathrm{O} \mathrm{H} \leftrightarrow \mathrm{SC}_{3} \mathrm{H}_{5} \mathrm{OH}+\dot{\mathrm{H}}$

- $\mathrm{C}_{3} \mathrm{H}_{6}+\dot{\mathrm{O}} \mathrm{H} \leftrightarrow \mathrm{CH}_{3} \mathrm{CHO}+\dot{\mathrm{C}} \mathrm{H}_{3}$

In this study, rate constants for the above reactions have been adopted from the theoretical study of Zádor et al. [47]. Zádor et al. stated a 50:50 branching ratio for hydroxyl radical addition to propene to form the two $\dot{\mathrm{C}}_{3} \mathrm{H}_{7} \mathrm{O}$ radicals via addition to the terminal or central carbon atom. Addition to the terminal carbon results in the formation of the $\mathrm{C}_{3} \mathrm{H}_{6} \mathrm{OH} 1-2$ radical $\left(\mathrm{CH}_{3} \mathrm{C} \mathrm{HCH}_{2} \mathrm{OH}\right)$, which reacts with molecular oxygen to form propanal 
and a hydroperoxyl radical. Addition to the central carbon results in the formation of the $\mathrm{C}_{3} \mathrm{H}_{6} \mathrm{OH} 2-1$ radical $\left(\mathrm{CH}_{3} \mathrm{CH}(\mathrm{OH}) \mathrm{CH}_{2}\right)$ which also reacts with $\mathrm{O}_{2}$ and results in the formation of acetone and a hydroperoxyl radical. In this study we use a branching ratio of 75:25 in favor of addition to the terminal carbon. This is consistent with the experimental study by Loison et al. [48], who stated that $72 \pm 16 \%$ of OH addition to propene proceeds via addition to the terminal $\mathrm{C}$ atom. The rate constants for the consumption of these radicals with molecular oxygen have been adopted from the study by Frassoldati et al. [49]. Above $1000 \mathrm{~K}$, hydroxyl radical addition to propene is not a major consumption pathway and only a small amount $(\approx 5 \%)$ of the $\mathrm{C}_{3} \mathrm{H}_{6}+\mathrm{OH}$ flux proceeds via addition reactions, resulting in the formation of vinyl alcohol and a methyl radical.

\subsection{5. $\mathrm{C}_{3} \mathrm{H}_{6}+\mathrm{HO}_{2} \leftrightarrow$ Products}

- $\mathrm{C}_{3} \mathrm{H}_{6}+\mathrm{HO}_{2} \leftrightarrow \dot{\mathrm{C}}_{3} \mathrm{H}_{5}-\mathrm{a}+\mathrm{H}_{2} \mathrm{O}_{2}$

- $\mathrm{C}_{3} \mathrm{H}_{6}+\mathrm{HO}_{2} \leftrightarrow \dot{\mathrm{C}}_{3} \mathrm{H}_{5}-\mathrm{S}+\mathrm{H}_{2} \mathrm{O}_{2}$

- $\mathrm{C}_{3} \mathrm{H}_{6}+\mathrm{HO}_{2} \leftrightarrow \dot{\mathrm{C}}_{3} \mathrm{H}_{5}-\mathrm{t}+\mathrm{H}_{2} \mathrm{O}_{2}$

- $\mathrm{C}_{3} \mathrm{H}_{6}+\mathrm{HO}_{2} \leftrightarrow \dot{\mathrm{C}}_{3} \mathrm{H}_{6} \mathrm{OOH} 2-1$

- $\mathrm{C}_{3} \mathrm{H}_{6}+\mathrm{HO}_{2} \leftrightarrow \mathrm{C}_{3} \mathrm{H}_{6} \mathrm{O} 1-2+\dot{\mathrm{OH}}$

- $\mathrm{C}_{3} \mathrm{H}_{6}+\mathrm{HO}_{2} \leftrightarrow \mathrm{i}_{3} \dot{\mathrm{H}}_{7} \dot{\mathrm{O}}_{2}$

- $\mathrm{C}_{3} \mathrm{H}_{6}+\mathrm{HO}_{2} \leftrightarrow \mathrm{i}_{3} \mathrm{H}_{7}+\mathrm{O}_{2}$

- $\dot{\mathrm{C}}_{3} \mathrm{H}_{6} \mathrm{OOH} 2-1 \leftrightarrow \mathrm{C}_{3} \mathrm{H}_{6} \mathrm{O} 1-2+\dot{\mathrm{OH}}$

Reactions that involve the hydroperoxyl radical are most influential at elevated pressures and lower temperatures. Under these conditions stabilization of $\dot{\mathrm{H}}+\mathrm{O}_{2}(+\mathrm{M}) \leftrightarrow \mathrm{HO}_{2}(+\mathrm{M})$ is favored over the chain branching reaction $\dot{\mathrm{H}}+\mathrm{O}_{2} \leftrightarrow \mathrm{O}^{*}+\dot{\mathrm{O}} \mathrm{H}$.

The rate constants for the addition and abstraction reactions of propene and hydroperoxyl radicals are adopted from the theoretical study of Zádor et al. [51]. The addition rate constants are pressure dependent. The rate constant for the abstraction reaction forming allyl radical was decreased by a factor of 2.5. This was necessary in order to best match experimental data, Figure 4. The rate constant for the abstraction reaction of propene and a hydroperoxyl radical was previously estimated based on analogy to the reaction of toluene with hydroperoxyl radical [50], while the previous addition reaction rate constant was adopted from Baldwin et al. [52].

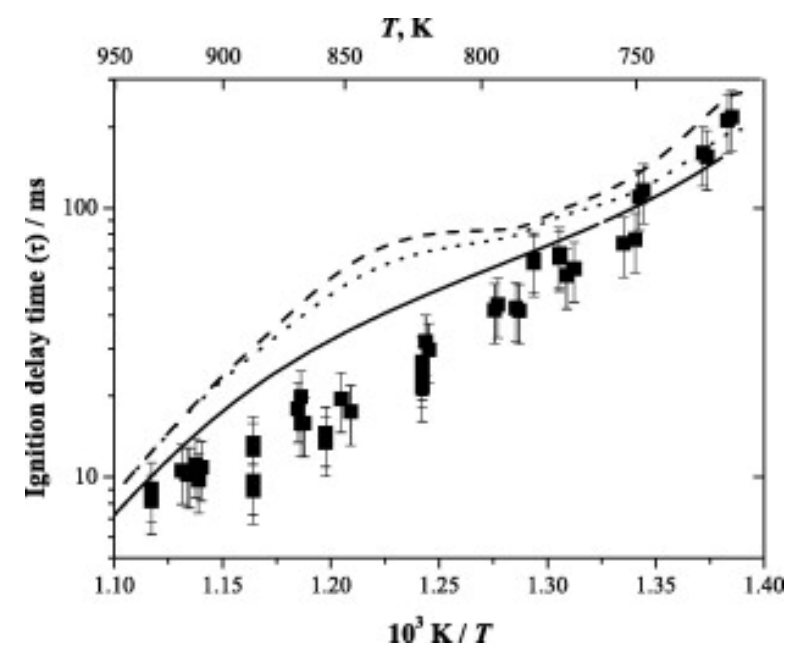

Figure 4. Effect of changing the $\mathrm{C}_{3} \mathrm{H}_{6}+\mathrm{HO}_{2}$ rate constants on predicted RCM ignition delay times for fuel/air, $p=40 \mathrm{~atm}, \phi=1$ mixture (Mix 11 [10]). - This study, - - - previous [32], $\cdots$ Zádor et al. [51] abstraction rate constant. 


\subsection{6. $\mathrm{C}_{3} \mathrm{H}_{6}+\mathrm{O}_{2} \leftrightarrow$ Products}

For hydrogen atom abstraction by molecular oxygen, only the reaction resulting in the formation of allyl and hydroperoxyl radicals was found to be sensitive, the other pathways were not competitive.

Baulch et al. [53] and Tsang [9] reported rate constants based on extensive literature reviews. Barbé et al. [54] studied this reaction experimentally. They carried out a measurement at $800 \mathrm{~K}$ using a conventional static system and their results showed good agreement with a previous experimental measurement from Stothard and Walker [55], who measured rate constants in the temperature range 673-793 K. Goldsmith et al. [56] investigated this reaction theoretically as part of their study of the reactions between allyl and hydroperoxyl radicals. In order to directly compare this rate constant, it was written in the opposite direction using the CHEMRev software [57].

This reaction has a very similar $\Delta \mathrm{rH}^{\circ}$ to the reaction of toluene and molecular oxygen forming benzyl and hydroperoxyl radicals. It also has the same number of hydrogen atoms available for abstraction. As discussed by Carstensen and Dean [59], there is a linear relationship between barrier height and heat of reaction for hydrogen atom abstraction from $\mathrm{C}-\mathrm{H}$ bond types. It could be argued therefore, that the reaction of propene and molecular oxygen should have a similar rate constant to the reaction toluene and molecular oxygen. Figure 5 compares $\mathrm{C}_{3} \mathrm{H}_{6}+\mathrm{O}_{2}[53-56]$ and toluene $+\mathrm{O}_{2}[58]$ rate constants.

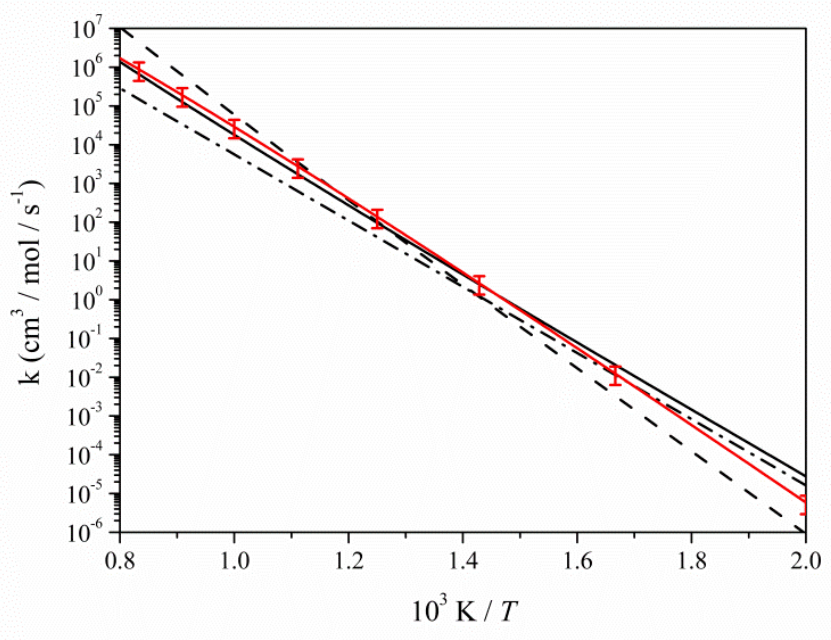

Figure 5. $\mathrm{C}_{3} \mathrm{H}_{6}+\mathrm{O}_{2}$ rate constant comparison. This study ( $\left.\pm 50 \%\right),-$ Goldsmith et al. [56], - - - (Toluene $+\mathrm{O}_{2}$ ) Oehlschlaeger et al. [58], -. - Stothard and Walker [55].

The rate constant adopted in this study is estimated to best fit experimental data over a wide range of conditions from the jet-stirred and flow reactors and shock tube. It is compared with rate constants from the literature in Figure 5. There is significant overlap over the temperature range $800-1200 \mathrm{~K}$ between the measured rate constant for toluene $+\mathrm{O}_{2}$ from Oehlschlaeger et al. [58] and the calculated rate constant from Goldsmith et al. for $\mathrm{C}_{3} \mathrm{H}_{6}+\mathrm{O}_{2}[56]$ above $1200 \mathrm{~K}$.

Inclusion of the different rate constants results in reasonable agreement under JSR conditions as shown in Figure 6(a). However, at high-pressure and relatively high-temperatures in the shock tube, Figure 6(b), inclusion of the previous rate constant or the values from Stothard and Walker and Baulch et al. results in the under prediction of reactivity. The recommendation from Goldsmith et al. results in ignition delay time 
predictions that are slower than the measurements by approximately $20-30 \%$, but this could be considered as reasonable agreement with the data.

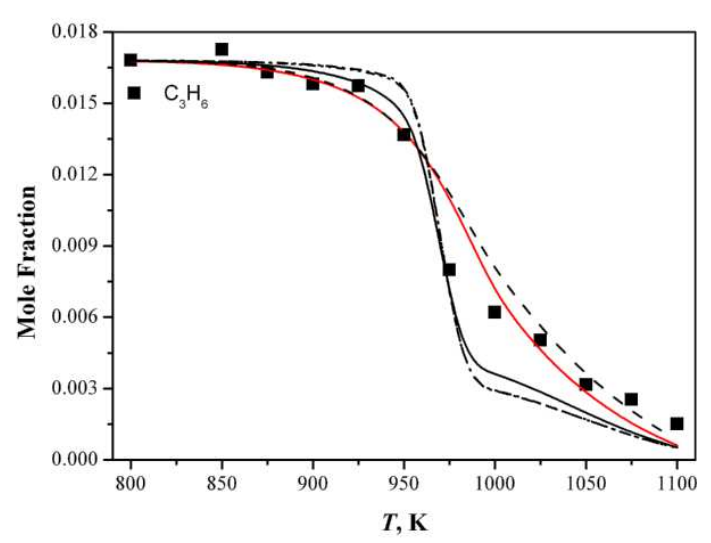

(a) JSR: $\phi=1.68, p=1 \mathrm{~atm}$.

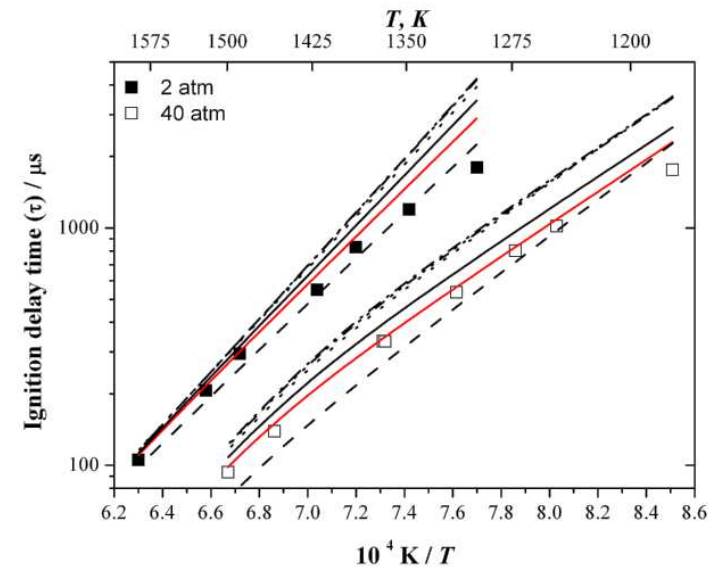

(b) Shock tube: $\phi=1, p=2$ and 10 atm (Mix 15 and 19 Part II Erreur! Source du renvoi introuvable.).

Figure 6. Effect of changing the $\mathrm{C}_{3} \mathrm{H}_{6}+\mathrm{O}_{2}$ rate constant on predicted JSR species profiles and predicted shock tube ignition delay times. This study, — Goldsmith et al. [56], - - - (Toluene $+\mathrm{O}_{2}$ ) Oehlschlaeger et al. [58], - - Stothard and Walker [55].

The rate constant for hydrogen atom abstraction by molecular oxygen from toluene from the study of Oehlschlaeger et al. also results in relatively good agreement with the ignition delay time data, but predicts ignition delay times that are approximately $20 \%$ faster than the measurements at $40 \mathrm{~atm}$. The rate constant adopted in this study is estimated in order to best match experimental data, but we believe it requires further study.

\subsection{7. $\mathrm{C}_{3} \mathrm{H}_{6}+\mathrm{O} * \leftrightarrow$ Products}

Rate constants for hydrogen atom abstraction by atomic oxygen are adopted from the review by Tsang [9]. These reactions did not show significant sensitivity during the course of this study.

Oxygen atom can also add to propene resulting in the formation of the following product sets:

- $\mathrm{C}_{3} \mathrm{H}_{6}+\mathrm{O} " \leftrightarrow \dot{\mathrm{C}}_{2} \mathrm{H}_{5}+\mathrm{HC} \mathrm{O}$

- $\mathrm{C}_{3} \mathrm{H}_{6}+\mathrm{O} * \leftrightarrow \mathrm{CH}_{2} \mathrm{CO}+\dot{\mathrm{C}} \mathrm{H}_{3}+\dot{\mathrm{H}}$

- $\mathrm{C}_{3} \mathrm{H}_{6}+\mathrm{O} * \leftrightarrow \mathrm{CH}_{3} \mathrm{CHCO}+\dot{\mathrm{H}}+\dot{\mathrm{H}}$

Oxygen atom addition reactions are chain branching reactions; they result in the formation of two or more radicals via the three pathways shown above. To our knowledge there is very little in the way of previous measurements or calculations of rate constants for these reactions in the literature. The recommendations in this study are estimated by analogy with the reactions of ethylene and atomic oxygen which are adopted from the study of Baulch et al. [16]. Savee et al. [60] studied the reaction of propene and atomic oxygen at 4 Torr and $298 \mathrm{~K}$, and reported three bi-molecular product sets: $\dot{\mathrm{C}}_{3}+\dot{\mathrm{C}}_{2} \mathrm{CHO}, \dot{\mathrm{C}}_{2} \mathrm{H}_{5}+\mathrm{HCO}$, and $\mathrm{H}_{2}+\mathrm{CH}_{3} \mathrm{CHCO}$ similar to those mentioned above and the collisional stabilization products methyloxirane and propanal. Exclusion of the collisional stabilization products may be a possible reason the current mechanism under-predicts the 
propanal species profiles. We recommend further study of this reaction system under combustion relevant conditions.

\section{3. $\dot{\mathrm{C}}_{3} \mathrm{H}_{5} \leftrightarrow$ Products}

- $\mathrm{C}_{3} \mathrm{H}_{4}-\mathrm{a}+\dot{\mathrm{H}} \leftrightarrow \dot{\mathrm{C}}_{3} \mathrm{H}_{5}-\mathrm{a}$

- $\mathrm{C}_{3} \mathrm{H}_{4}-\mathrm{a}+\dot{\mathrm{H}} \leftrightarrow \mathrm{C}_{3} \mathrm{H}_{4}-\mathrm{p}+\dot{\mathrm{H}}$

- $\mathrm{C}_{3} \mathrm{H}_{4}-\mathrm{a}+\dot{\mathrm{H}} \leftrightarrow \mathrm{C}_{2} \mathrm{H}_{2}+\dot{\mathrm{C}} \mathrm{H}_{3}$

- $\mathrm{C}_{3} \mathrm{H}_{4}-\mathrm{a}+\dot{\mathrm{H}} \leftrightarrow \dot{\mathrm{C}}_{3} \mathrm{H}_{5}-\mathrm{t}$

- $\mathrm{C}_{3} \mathrm{H}_{4}-\mathrm{p}+\dot{\mathrm{H}} \leftrightarrow \dot{\mathrm{C}}_{3} \mathrm{H}_{5}-\mathrm{t}$

- $\mathrm{C}_{3} \mathrm{H}_{4}-\mathrm{p}+\dot{\mathrm{H}} \leftrightarrow \dot{\mathrm{C}}_{3} \mathrm{H}_{5}-\mathrm{S}$

- $\mathrm{C}_{2} \mathrm{H}_{2}+\dot{\mathrm{C}} \mathrm{H} 3 \leftrightarrow \dot{\mathrm{C}}_{3} \mathrm{H}_{5}-\mathrm{S}$

$\dot{\mathrm{C}}_{3} \mathrm{H}_{5}-\mathrm{x}$ radicals (1-, 2-, 3-propenyl) can decompose to produce either allene and a $\dot{H}$ atom or propyne and a $\dot{H}$ atom. Other reactions that occur on the $\dot{\mathrm{C}}_{3} \mathrm{H}_{5}$ potential energy surface include the reaction of the $\mathrm{C}_{3} \mathrm{H}_{4}$ isomers and atomic hydrogen to form methyl radical and acetylene and the $\dot{H}$ atom catalyzed isomerization reaction between allene and propyne. As observed during the course of this study, the $\dot{\mathrm{C}}_{3} \mathrm{H}_{5}-\mathrm{x}$ decomposition reactions only become competitive with the reactions of $\dot{\mathrm{C}}_{3} \mathrm{H}_{5}-\mathrm{a}+\mathrm{HO}_{2}$ and $\dot{\mathrm{C}}_{3} \mathrm{H}_{5}-\mathrm{s}$ or $\dot{\mathrm{C}}_{3} \mathrm{H}_{5}-\mathrm{t}+\mathrm{O}_{2}$ at a high temperatures. Miller et al. [61] carried out an extensive study of the $\dot{C}_{3} \mathrm{H}_{5}$ radical potential energy surface using RRKM theory and master-equation calculations to determine the rate coefficients. The authors carried out an extensive literature review of experimental and theoretical studies showing excellent agreement between their results and the available experimental results. These rate constants have been adopted in the current mechanism.

\section{4. $\dot{\mathrm{C}}_{3} \mathrm{H}_{5}-\mathrm{a}+\dot{\mathrm{R}} \leftrightarrow$ Products}

\subsection{1. $\dot{\mathrm{C}}_{3} \mathrm{H}_{5}-\mathrm{a}+\dot{\mathrm{C}} \mathrm{H}_{3} \leftrightarrow \mathrm{C}_{4} \mathrm{H}_{8}-1$}

The recombination reaction of allyl and methyl radicals to give 1-butene is an important inhibiting reaction for propene combustion, especially at lower temperatures, Figs. 1(b) and 18. The current mechanism predicts that this reaction produces nearly all of the butene detected in the JSR experiments. This chain terminating reaction acts to inhibit reactivity for ignition delay time measurements. The rate constant included is from Tsang [9].

\subsection{2. $\dot{\mathrm{C}}_{3} \mathrm{H}_{5}-\mathrm{a}+\mathrm{H} \dot{\mathrm{O}}_{2} \leftrightarrow$ Products}

The reactions of allyl and hydroperoxyl radicals are observed to be important across a range of conditions, especially at low to intermediate temperatures, Figs. 1(a) and 18. At approximately $875 \mathrm{~K}$ and $1 \mathrm{~atm}$ in a JSR, the reaction of allyl and hydroperoxyl radicals accounts for approximately half of all allyl radical consumption, Figure 18. We have adopted the pressure dependent rate constants for the bimolecular reactions of allyl radical with hydroperoxyl radical, the thermal decomposition of allyl hydroperoxide $\left(\mathrm{aC}_{3} \mathrm{H}_{5} \mathrm{OOH}\right)$, and the unimolecular reactions of allyloxy $\left(\mathrm{C}_{3} \mathrm{H}_{5} \dot{\mathrm{O}}\right)$ radical from the study of Goldsmith et al. [56]. It is the most recent and comprehensive investigation of the allyl radical plus hydroperoxyl radical system. 
$\dot{\mathrm{C}}_{3} \mathrm{H}_{5}-\mathrm{a}+\mathrm{HO}_{2}$

- $\dot{\mathrm{C}}_{3} \mathrm{H}_{5}-\mathrm{a}+\mathrm{HO}_{2} \leftrightarrow \mathrm{C}_{3} \mathrm{H}_{5} \dot{\mathrm{O}}+\dot{\mathrm{OH}}$

- $\dot{\mathrm{C}}_{3} \mathrm{H}_{5}-\mathrm{a}+\mathrm{HO}_{2} \leftrightarrow \mathrm{aC}_{3} \mathrm{H}_{5} \mathrm{OOH}$

- $\dot{\mathrm{C}}_{3} \mathrm{H}_{5}-\mathrm{a}+\mathrm{HO}_{2} \leftrightarrow \mathrm{C}_{2} \mathrm{H}_{3} \mathrm{CHO}+\mathrm{H}_{2} \mathrm{O}$

$\mathrm{aC} 3 \mathrm{H} 5 \mathrm{OOH}$

- $\mathrm{aC}_{3} \mathrm{H}_{5} \mathrm{OOH} \leftrightarrow \mathrm{C}_{2} \mathrm{H}_{3} \mathrm{CHO}+\mathrm{H}_{2} \mathrm{O}$

- $\mathrm{aC}_{3} \mathrm{H}_{5} \mathrm{OOH} \leftrightarrow \mathrm{C}_{3} \mathrm{H}_{5} \dot{\mathrm{O}}+\dot{\mathrm{OH}}$

As shown in Figure 7, at elevated temperatures and low-pressures, allyl radical reacts with hydroperoxyl radical to form allyloxy and a hydroxyl radical. However, as temperatures decrease and pressures increase the formation of the chemically activated adduct allyl hydroperoxide becomes dominant. Allyl hydroperoxide subsequently decomposes to give allyloxy and hydroxyl radicals.

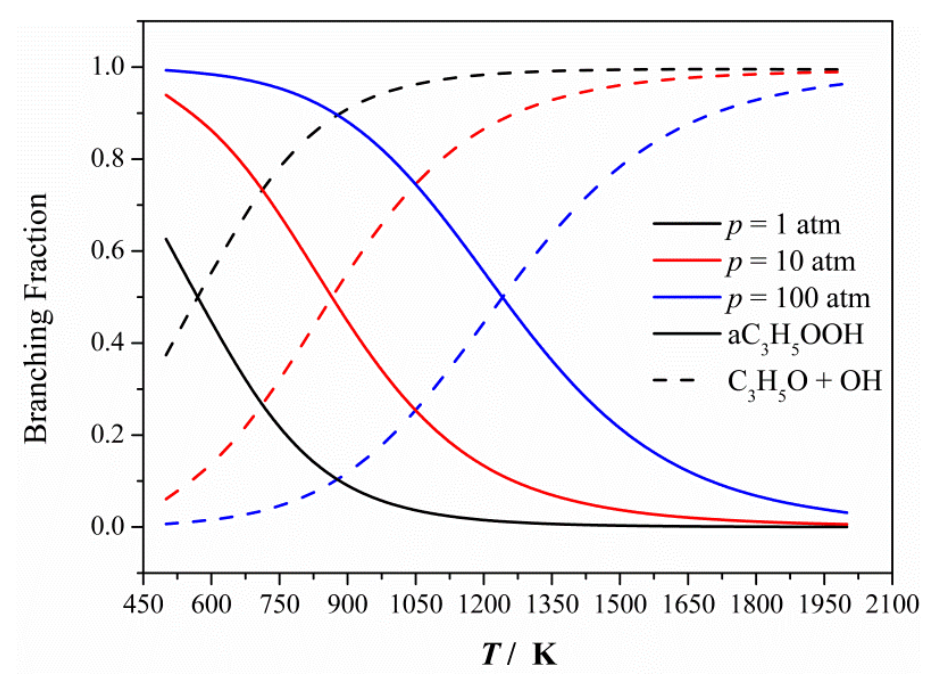

Figure 7. Branching ratio of $\dot{\mathrm{C}}_{3} \mathrm{H}_{5}-\mathrm{a}+\mathrm{HO}_{2} \leftrightarrow$ Products.

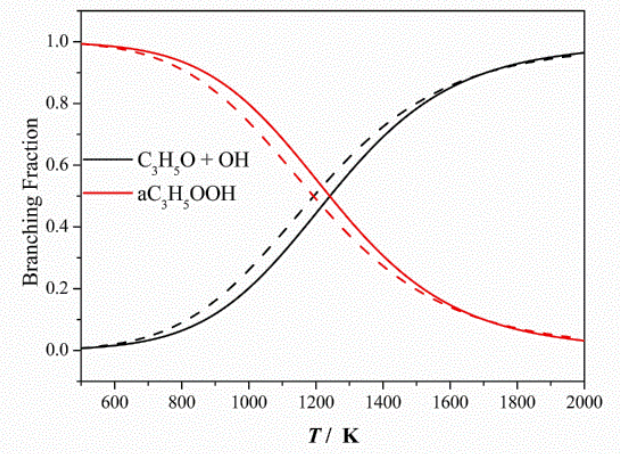

(a) Comparison of branching ratio at $100 \mathrm{~atm}$.

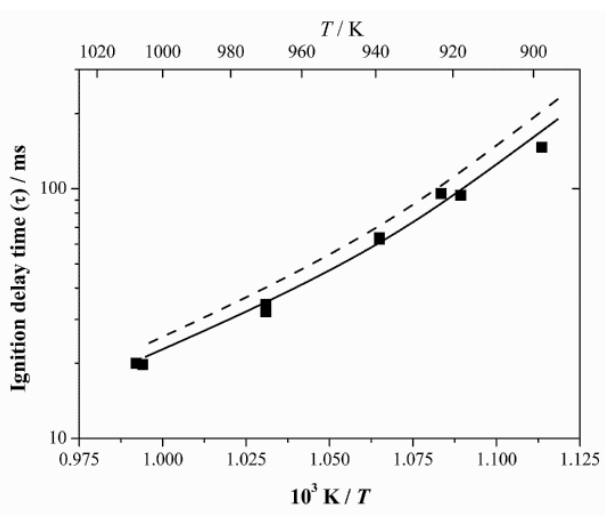

(b) RCM: fuel $/ 4 \% \mathrm{O}_{2}, \phi=1.0 p=40 \mathrm{~atm}$.

Figure 8. Altering the $\dot{\mathrm{C}}_{3} \mathrm{H}_{5}-\mathrm{a}+\mathrm{HO}_{2}$ branching ratio and its effect on predicted RCM ignition delay times (Mix 11 [10]). — This study, - - - Goldsmith et al. [55]. 
The branching ratio for the $\dot{\mathrm{C}}_{3} \mathrm{H}_{5}-\mathrm{a}+\mathrm{HO}_{2}$ reaction between the allyloxy producing channel and the allyl hydroperoxide producing channel has been altered slightly from the recommendation of Goldsmith et al. An additional $5 \%$ of the flux now proceeds via the allyl hydroperoxide channel at the highest pressure, Figure 8(a). This has resulted in better agreement with RCM ignition delay time data, as shown in Figure 8(b). At combustion relevant conditions both of the major channels for the reaction of allyl radical and hydroperoxyl radical act to promote reactivity as they ultimately convert a stable allyl radical to a reactive hydroxyl radical.

\section{$\mathrm{C}_{3} \mathrm{H}_{5} \mathrm{O} \leftrightarrow$ Products}

- $\mathrm{C}_{3} \mathrm{H}_{5} \mathrm{O} \leftrightarrow \dot{\mathrm{C}}_{2} \mathrm{H}_{3}+\mathrm{CH}_{2} \mathrm{O}$

- $\mathrm{C}_{3} \mathrm{H}_{5} \dot{\mathrm{O}} \leftrightarrow \mathrm{C}_{2} \mathrm{H}_{3} \mathrm{O} \dot{\mathrm{C}} \mathrm{H}_{2}$

- $\mathrm{C}_{3} \mathrm{H}_{5} \mathrm{O} \leftrightarrow \dot{\mathrm{CH}}_{2} \mathrm{CH}_{2} \mathrm{CHO}$

- $\mathrm{C}_{3} \mathrm{H}_{5} \mathrm{O} \leftrightarrow \mathrm{C}_{2} \mathrm{H}_{3} \mathrm{CHO}+\dot{\mathrm{H}}$

- $\mathrm{C}_{3} \mathrm{H}_{5} \dot{\mathrm{O}} \leftrightarrow \mathrm{C}_{2} \mathrm{H}_{4}+\mathrm{H} \dot{\mathrm{CO}}$

Allyloxy radical decomposes to give bi-molecular products such as vinyl radical and formaldehyde, acrolein and atomic hydrogen, and ethylene and formyl radical. It can also undergo isomerisation to give vinoxylmethyl and formyl-ethyl radicals. The rate constants for these reactions were also adopted from the study by Goldsmith et al. [56].

In AramcoMech 1.3, the reaction of allyl and hydroperoxyl radicals consisted of one channel producing allyloxy radical $\left(\mathrm{C}_{3} \mathrm{H}_{5} \mathrm{O}\right)$ and hydroxyl radicals via an estimated high-pressure limit rate constant. Allyloxy radical was consumed via decomposition reactions or via ÖH addition to form allyl hydroperoxide. Inclusion of the previous rate constants into the current kinetic scheme results in a significant increase in reactivity as shown in Figure 9.

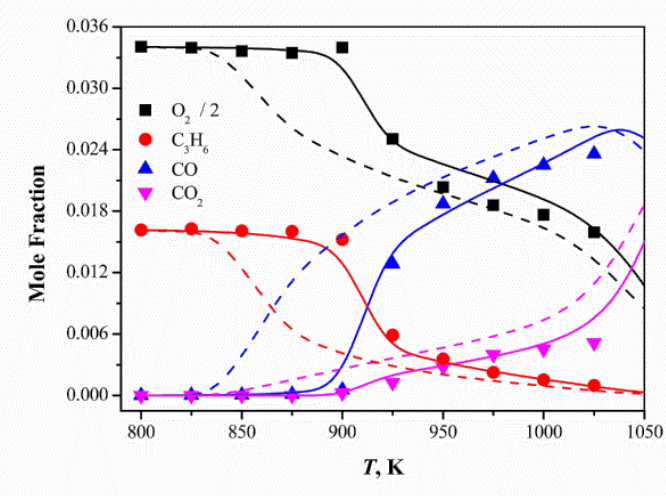

(a) JSR: $\phi=1.07, p=1 \mathrm{~atm}$.

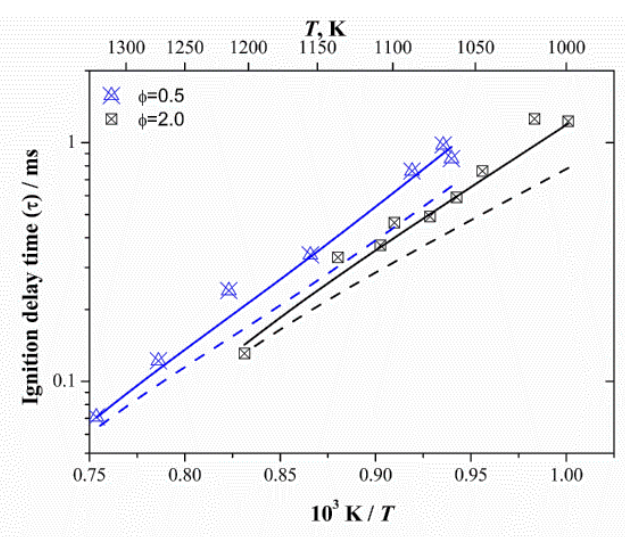

(b) ST: $\phi=0.5$ and 2.0 fuel/air, $p=40$ atm.

Figure 9. Effect of using current — and previous [32] - - $\dot{\mathrm{C}}_{3} \mathrm{H}_{5}-\mathrm{a}+\mathrm{H} \dot{\mathrm{O}}_{2}$ rate constants on predicted JSR species profiles and shock tube ignition delay times (Mix 27 and 30 [10]).

Other rate constants in the allyl $+\mathrm{HO}_{2}$ system which were not found to be competitive during the course of this study but are incorporated into the mechanism from the study by Goldsmith et al. [56] include $\mathrm{C}_{2} \mathrm{H}_{3} \mathrm{O} \dot{\mathrm{C}} \mathrm{H}_{2}$ and $\dot{\mathrm{C}} \mathrm{H}_{2} \mathrm{CH}_{2} \mathrm{CHO}$ decomposition, and the reactions of vinyl radical with formaldehyde. 


\subsection{3. $\dot{\mathrm{C}}_{3} \mathrm{H}_{5}+\mathrm{O}_{2} \leftrightarrow$ Products}

The reactions of allyl radical and molecular oxygen were not found to be particularly sensitive during the course of this study. The reactions of allyl radical with hydroperoxyl radical or recombination reactions are generally more competitive. The rate constants for the $\dot{\mathrm{C}}_{3} \mathrm{H}_{5}-\mathrm{a}+\mathrm{O}_{2}$ reactions have been adopted from the study by Bozzelli and Dean [63].

To the best of our knowledge there have been no previous studies of the reactions of 2-propenyl radical $\left(\dot{\mathrm{C}}_{3} \mathrm{H}_{5}-\right.$ t) or 1-propenyl radical $\left(\dot{\mathrm{C}}_{3} \mathrm{H}_{5}-\mathrm{s}\right)$ with molecular oxygen. During a recent study of ethylene combustion, it was shown that the vinyl radical was consumed almost entirely by reactions with molecular oxygen [32,34]. Similarly, the current mechanism predicts that under JSR and flow reactor conditions $\dot{\mathrm{C}}_{3} \mathrm{H}_{5}$-t and $\dot{\mathrm{C}}_{3} \mathrm{H}_{5}$-S are almost exclusively consumed by reaction with molecular oxygen, Figures 18 and 26 . The total rate constants for the reactions of both $\dot{\mathrm{C}}_{3} \mathrm{H}_{5}$-t and $\dot{\mathrm{C}}_{3} \mathrm{H}_{5}$-s with molecular oxygen recommended in this study are estimated by analogy to the reaction of vinyl radical and molecular oxygen from the high-level ab initio study by Klippenstein et al. [64], Figure 10. The authors stated that the predicted crossover temperature between the aldehyde producing channel and the atomic oxygen producing channel occurs at a temperature range of 1200$2500 \mathrm{~K}$. The wide range is due to a $4 \mathrm{kcal} / \mathrm{mol}$ uncertainty in the energy barrier to the transition state. Due to the importance of these reactions we recommend further study of the total rate constants, the product channels, and the branching ratio between these channels. The effect of including the updated rate constants is included in Figure 12.

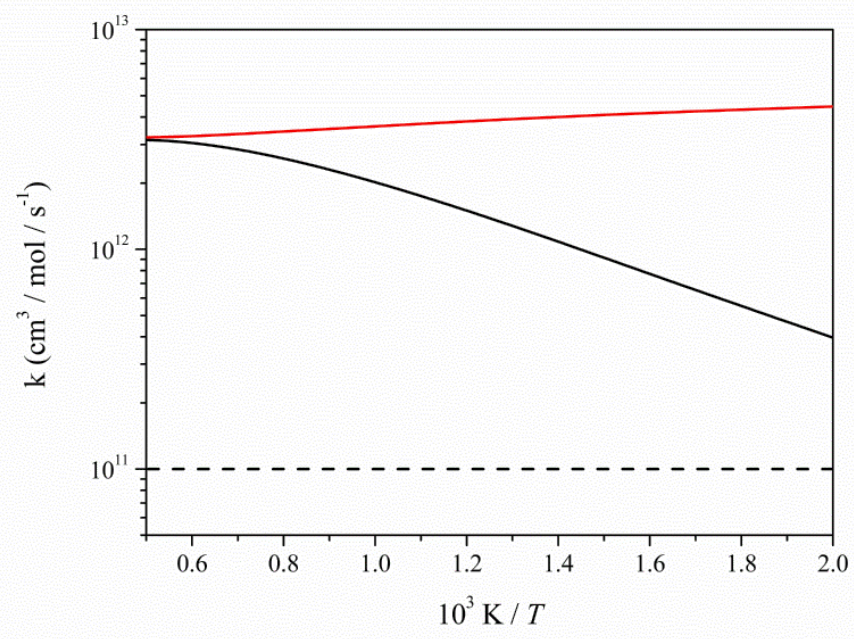

Figure 10. Total rate constants for $\dot{\mathrm{C}}_{3} \mathrm{H}_{5}-\mathrm{t}+\mathrm{O}_{2}$ and $\dot{\mathrm{C}}_{3} \mathrm{H}_{5}-\mathrm{s}+\mathrm{O}_{2}$. This study (analogy to $\dot{\mathrm{C}}_{2} \mathrm{H}_{3}+\mathrm{O}_{2}$ [64]), previous $\dot{\mathrm{C}}_{3} \mathrm{H}_{5}-\mathrm{t}+\mathrm{O}_{2}$, - - - previous $\dot{\mathrm{C}}_{3} \mathrm{H}_{5}-\mathrm{s}+\mathrm{O}_{2}$ recommendation [32].

$\dot{\mathrm{C}}_{3} \mathrm{H}_{5}-\mathrm{t}+\mathrm{O}_{2} \leftrightarrow$ Products

- $\dot{\mathrm{C}}_{3} \mathrm{H}_{5}-\mathrm{t}+\mathrm{O}_{2} \leftrightarrow \mathrm{CH}_{3} \mathrm{COC}^{-} \mathrm{H}_{2}+\mathrm{O}$ "

- $\dot{\mathrm{C}}_{3} \mathrm{H}_{5}-\mathrm{t}+\mathrm{O}_{2} \leftrightarrow \mathrm{CH}_{3} \dot{\mathrm{CO}}+\mathrm{CH}_{2} \mathrm{O}$

- $\dot{\mathrm{C}}_{3} \mathrm{H}_{5}-\mathrm{t}+\mathrm{O}_{2} \leftrightarrow \mathrm{C}_{3} \mathrm{H}_{4}-\mathrm{a}+\mathrm{HO}_{2}$

The $\dot{\mathrm{C}}_{3} \mathrm{H}_{5}$-t radical can react with molecular oxygen via three possible pathways. The acetyl radical and formaldehyde forming channel is chain propagating and inhibits reactivity, as it competes with a chain 
branching pathway that forms atomic oxygen and acetonyl radical. The third pathway is a minor one and yields allene and a hydroperoxyl radical. In order to best match experimental measurements in the flow reactor and the $\mathrm{RCM}$, the crossover temperature for the branching ratio between the chain branching channel $\left(\mathrm{CH}_{3} \mathrm{COCH}_{2}+\mathrm{O}^{\prime \prime}\right)$ and the propagating channel $\left(\mathrm{CH}_{3} \mathrm{CO}+\mathrm{CH}_{2} \mathrm{O}\right)$ has been reduced from $1200 \mathrm{~K}$ to $1000 \mathrm{~K}$ as recommended by Klippenstein et al. [64], Figure 11.

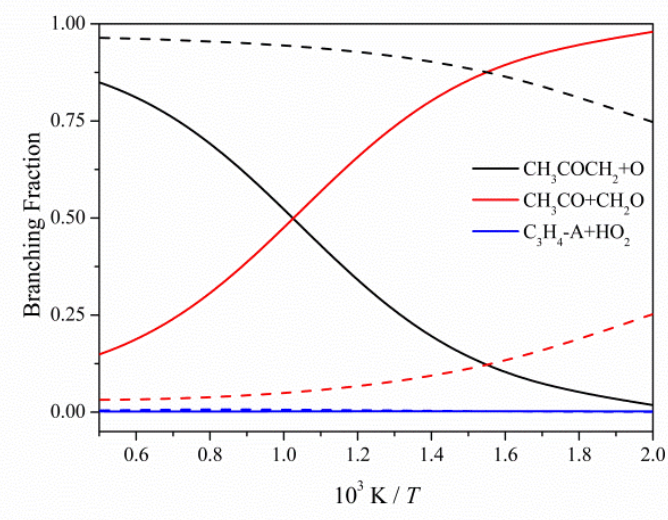

(a) $\dot{\mathrm{C}}_{3} \mathrm{H}_{5}-\mathrm{t}+\mathrm{O}_{2}$ branching ratio.

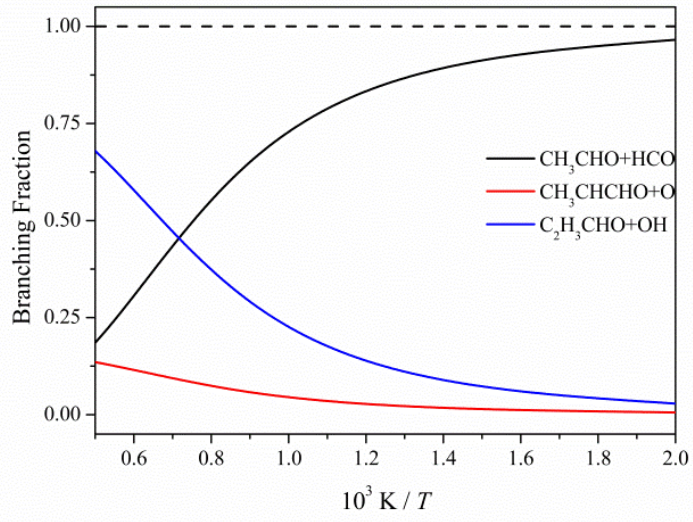

(b) $\dot{\mathrm{C}}_{3} \mathrm{H}_{5}-\mathrm{S}+\mathrm{O}_{2}$ branching ratio.

Figure 11. Branching ratios of the $\dot{\mathrm{C}}_{3} \mathrm{H}_{5}-\mathrm{t}+\mathrm{O}_{2}$ and $\dot{\mathrm{C}}_{3} \mathrm{H}_{5}-\mathrm{S}+\mathrm{O}_{2}$ reactions. - This study (analogy to $\dot{\mathrm{C}}_{2} \mathrm{H}_{3}+\mathrm{O}_{2}$ [64]), - - - AramcoMech 1.3 [32].

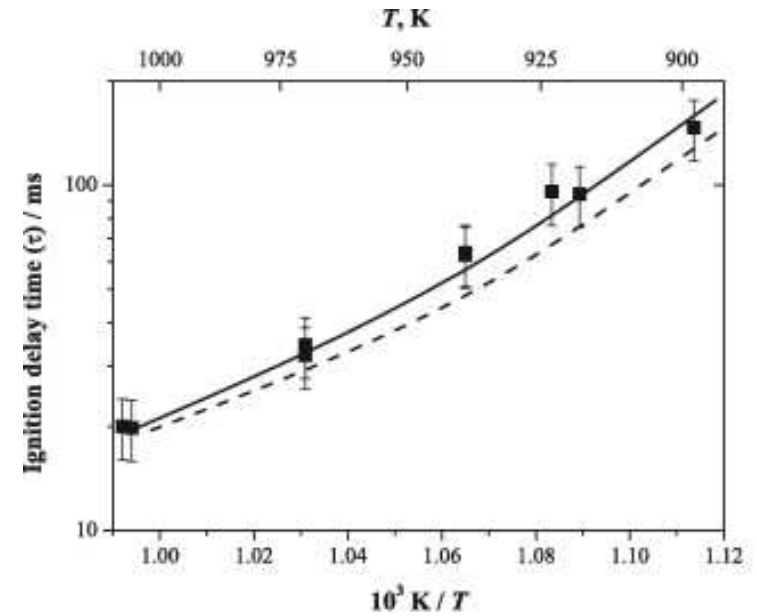

(a) $\mathrm{RCM}$ : fuel $/ 4 \% \mathrm{O}_{7}, \varphi=1.0 p=40 \mathrm{~atm}$.

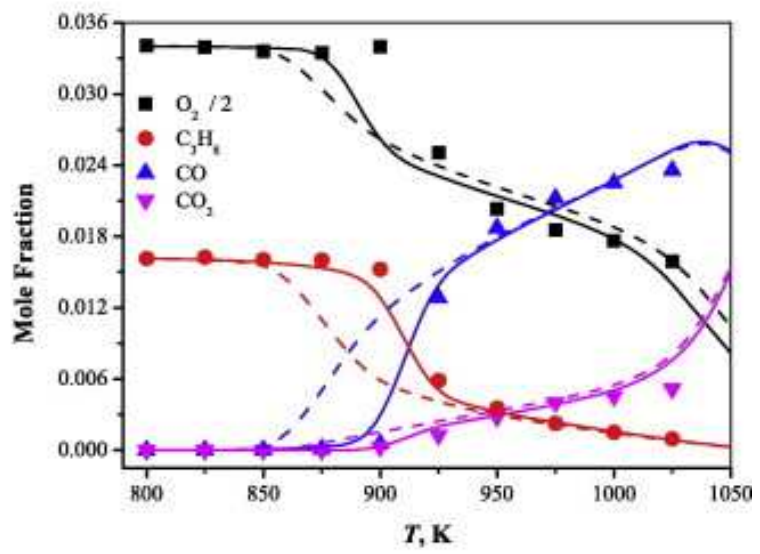

(b) JSR: $\varphi=1.07, p=1 \mathrm{~atm}$.

Figure 12. Effect of changing the $\dot{\mathrm{C}}_{3} \mathrm{H}_{5}-\mathrm{S}+\mathrm{O}_{2}$ and $\dot{\mathrm{C}}_{3} \mathrm{H}_{5}-\mathrm{t}+\mathrm{O}_{2}$ rate constants on predicted RCM ignition delay times (Mix 13 [10]) and JSR speciation measurements. - This study, - - previous $\dot{\mathrm{C}}_{3} \mathrm{H}_{5}-\mathrm{s}$ and $\dot{\mathrm{C}}_{3} \mathrm{H}_{5}-\mathrm{t}+\mathrm{O}_{2}$

[32].

In AramcoMech 1.3 the majority of the flux proceeded via the atomic oxygen producing channel at combustion relevant conditions and there was an over-prediction of reactivity, especially in the flow reactor. Sensitivity to the branching ratio between chain branching and chain propagating was observed at elevated pressures and relatively low temperatures, Figure $1(\mathrm{a})$.

$\dot{\mathrm{C}}_{3} \mathrm{H}_{5}-\mathrm{S}+\mathrm{O}_{2} \leftrightarrow$ Products 


\section{- $\dot{\mathrm{C}}_{3} \mathrm{H}_{5}-\mathrm{S}+\mathrm{O}_{2} \leftrightarrow \mathrm{CH}_{3} \mathrm{CHO}+\mathrm{HC} \mathrm{O}$}

- $\dot{\mathrm{C}}_{3} \mathrm{H}_{5}-\mathrm{S}+\mathrm{O}_{2} \leftrightarrow \mathrm{C}_{2} \mathrm{H}_{3} \mathrm{CHO}+\dot{\mathrm{OH}}$

- $\dot{\mathrm{C}}_{3} \mathrm{H}_{5}-\mathrm{S}+\mathrm{O}_{2} \leftrightarrow \mathrm{CH}_{3} \dot{\mathrm{C}} \mathrm{HCHO}+\mathrm{O}$

The $\dot{\mathrm{C}}_{3} \mathrm{H}_{5}$-s radical also reacts with molecular oxygen via three possible pathways, Figure 11 . The acetaldehyde and formyl radical producing channel is the main source of acetaldehyde in the JSR as predicted by the current mechanism, Figure 18. It is a chain propagating reaction and inhibits reactivity. The chain branching pathway results in the formation of $\mathrm{CH}_{3} \dot{\mathrm{C}} \mathrm{HCHO}$ and $\mathrm{OH}$ radicals while the minor channel forms acrolein and hydroxyl radical. The total rate constant for the reaction of $\dot{\mathrm{C}}_{3} \mathrm{H}_{5}$-s radical and molecular oxygen has also been estimated based on the reaction between vinyl and molecular oxygen from Klippenstein et al. [64].

\section{5. $1,5-\mathrm{C}_{6} \mathrm{H}_{10}$}

\subsection{1. $\mathrm{C}_{6} \mathrm{H}_{10} \leftrightarrow \dot{\mathrm{C}}_{3} \mathrm{H}_{5}-\mathrm{a}+\dot{\mathrm{C}}_{3} \mathrm{H}_{5}-\mathrm{a}$}

- $\dot{\mathrm{C}}_{3} \mathrm{H}_{5}-\mathrm{a}+\dot{\mathrm{C}}_{3} \mathrm{H}_{5}-\mathrm{a} \leftrightarrow \mathrm{C}_{6} \mathrm{H}_{10}$

- $\dot{\mathrm{C}}_{3} \mathrm{H}_{5}-\mathrm{a}+\dot{\mathrm{C}}_{3} \mathrm{H}_{5}-\mathrm{a} \leftrightarrow \mathrm{C}_{3} \mathrm{H}_{4}-\mathrm{a}+\mathrm{C}_{3} \mathrm{H}_{6}$

Allyl radicals can undergo self-recombination to form 1,5-hexadiene. This chain terminating reaction inhibits reactivity at low and intermediate temperatures. Allyl radical self-reaction can also result in the formation of allene and propene. However, this channel accounts for less than $5 \%$ of the total flux.

AramcoMech 1.3 did not include the allyl-allyl self-reaction, however, as significant amounts of 1,5-hexadiene were detected in the JSR it was necessary to include this reaction. In this study we have adopted a rate constant for allyl radical self-reaction based on the recommendations of two recent papers by Tranter and coworkers $[65,66]$. The decomposition of 1,5-hexadiene was investigated experimentally in a shock-tube [65] and theoretically with a Gorin-type RRKM calculation [66]. However, the rate constant adopted in this study is $30 \%$ less that of Lynch et al. [65]. This reduction is within the stated uncertainty and was required to match the high-pressure ignition delay time measurements.

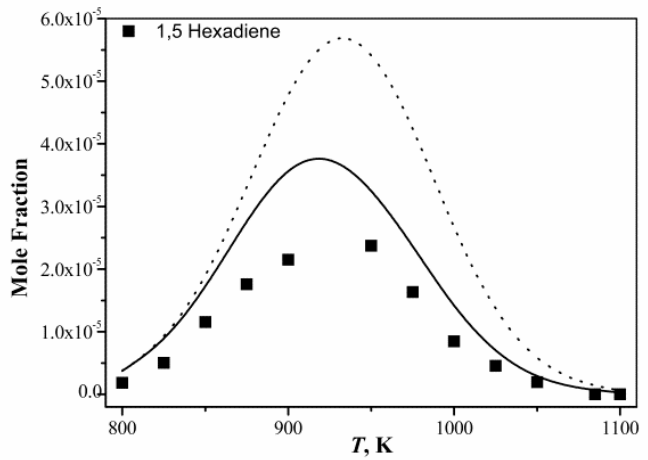

(a) JSR: $\phi=2.19, p=1 \mathrm{~atm}$.

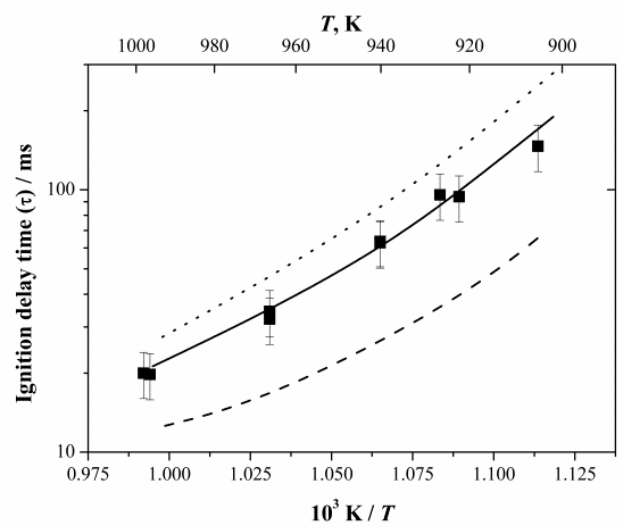

(b)RCM: $\phi=1.0,4 \% \mathrm{O}_{2}, p=40$ atm.

Figure 13. Effect of including the $\dot{\mathrm{C}}_{3} \mathrm{H}_{5}-\mathrm{a}+\dot{\mathrm{C}}_{3} \mathrm{H}_{5}-\mathrm{a} \leftrightarrow \mathrm{C}_{6} \mathrm{H}_{10}$ rate constant on predicted JSR species profiles and RCM ignition delay times (Mix 13 [10]). — This study, - - - excluding allyl recombination, $\cdots \cdots$ previous $\mathrm{C}_{6} \mathrm{H}_{10}$ thermochemistry. 
Tranter and co-workers highlighted the importance of 1,5-hexadiene thermochemistry in their study [65]. We have adopted their recommendation for the heat of formation and molar entropy. Figure 13 highlights the effect of thermochemistry. At $800 \mathrm{~K}$ using the standard molar entropy value from Lynch et al. results in a reduction of approximately a factor of two in the rate constant for the formation of 1,5-hexadiene.

\subsection{2. $\mathrm{C}_{6} \mathrm{H}_{10}$ sub-mechanism}

- $\mathrm{C}_{6} \mathrm{H}_{10}+\dot{\mathrm{H}} \leftrightarrow \dot{\mathrm{C}}_{6} \mathrm{H}_{9}+\mathrm{H}_{2}$

- $\mathrm{C}_{6} \mathrm{H}_{10}+\dot{\mathrm{C}} \mathrm{H}_{3} \leftrightarrow \dot{\mathrm{C}}_{6} \mathrm{H}_{9}+\mathrm{CH}_{4}$

- $\mathrm{C}_{6} \mathrm{H}_{10}+\mathrm{O} " \leftrightarrow \dot{\mathrm{C}}_{6} \mathrm{H}_{9}+\mathrm{O} \mathrm{H}$

- $\mathrm{C}_{6} \mathrm{H}_{10}+\mathrm{O} H \leftrightarrow \dot{\mathrm{C}}_{6} \mathrm{H}_{9}+\mathrm{H}_{2} \mathrm{O}$

- $\mathrm{C}_{6} \mathrm{H}_{10}+\mathrm{O}_{2} \leftrightarrow \dot{\mathrm{C}}_{6} \mathrm{H}_{9}+\mathrm{HO}_{2}$

- $\dot{\mathrm{C}}_{6} \mathrm{H}_{9} \leftrightarrow 1,3-\mathrm{C}_{4} \mathrm{H}_{6}+\dot{\mathrm{C}}_{2} \mathrm{H}_{3}$

The rate constants for hydrogen atom abstraction from 1,5-hexadiene by radical species have been adopted from the work of Orme and coworkers $[67,68]$. Rate constants for other reactions such as hydrogen atom abstraction by molecular oxygen have been estimated based on their BDE and the number of hydrogen atoms available for abstraction as described by Ingham et al. [69]. These reactions were not found to be sensitive for propene oxidation. The resulting $\dot{\mathrm{C}}_{6} \mathrm{H}_{9}$ radical decomposes to form 1,3-butadiene and a vinyl radical.

\subsection{Allene/propyne sub-mechanism}

Previously [32], rate constants for the allene/propyne sub-mechanism were adopted from various sources $[41,70,71]$. Hansen et al. [72] recently published a mechanism for the combustion of allene and propyne in flames. They reported rate constants for fuel consumption, allene and propyne isomerisation, reaction of propargyl radical with molecular oxygen, and of isomer specific formation of $\mathrm{C}_{6}$ aromatic species. We have adopted the Hansen et al. [72] sub-mechanism in the current kinetic scheme. For reactions that were not featured in the Hansen et al. study, such as hydrogen atom abstraction by molecular oxygen from both $\mathrm{C}_{3} \mathrm{H}_{4}$ isomers, rate constants have been estimated based on the bond dissociation energy (BDE) for the activation energy and the number of hydrogen atoms available for abstraction for the A-factor as described by Ingham et al. [69].

Hydroxyl radical addition rate constants are estimates $[73,74]$ while rate constants for abstraction by OH are described as analogous to reactions involving $\mathrm{C}_{3} \mathrm{H}_{6}$. Rate constants for propargyl and hydroperoxyl radical reactions are included using analogies to the reactions of allyl radical and $\mathrm{HO}_{2}$, which were adopted from Goldsmith et al. [75]. Further details of the $\mathrm{C}_{3} \mathrm{H}_{4}$ isomer sub-mechanism are included in the $\mathrm{PhD}$ thesis of Burke [76], which describes validation of the allene/propyne mechanism against speciation measurements in a JSR and ignition delay measurements in a shock tube. 


\section{Results and discussion}

\subsection{Jet-stirred reactor results}

Concentration profiles of stable species measured during the experiments have been simulated using the kinetic model developed during this study. Experimental measurements were obtained at four equivalence ratios, $\phi=0.64,1.07,1.68$, and 2.19 , over a temperature range of 800-1100 $\mathrm{K}$ and at near-atmospheric pressure. Figures 14 to 17 show the performance of the current mechanism, and Figure 19 compares its performance with that of AramcoMech 1.3 [32]. Overall there is good agreement between the current mechanism and the experimental measurements. The biggest discrepancy in its performance is the consistent under-prediction of benzene and propanal.

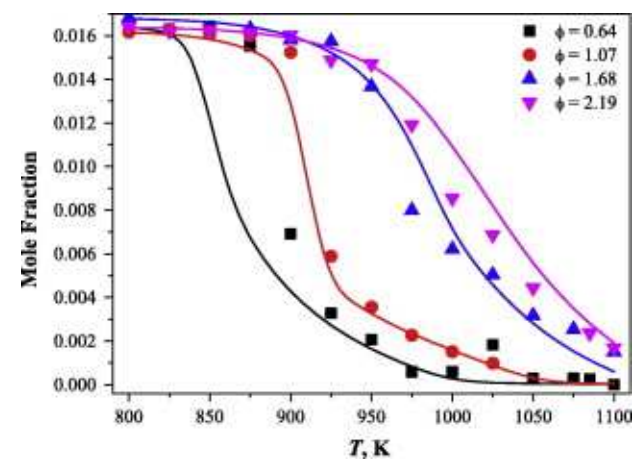

Figure 14. Comparison of $\approx 1.65 \% \mathrm{C}_{3} \mathrm{H}_{6}$ consumption at varying equivalence ratios, $\mathrm{p}=1.05 \mathrm{~atm}, \tau=2.0 \mathrm{~s}$. Symbols: JSR experimental measurements, lines: current mechanism predictions.

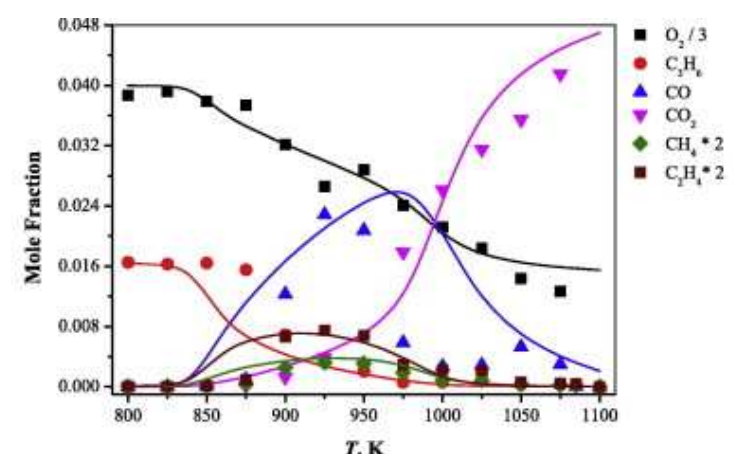

(a)

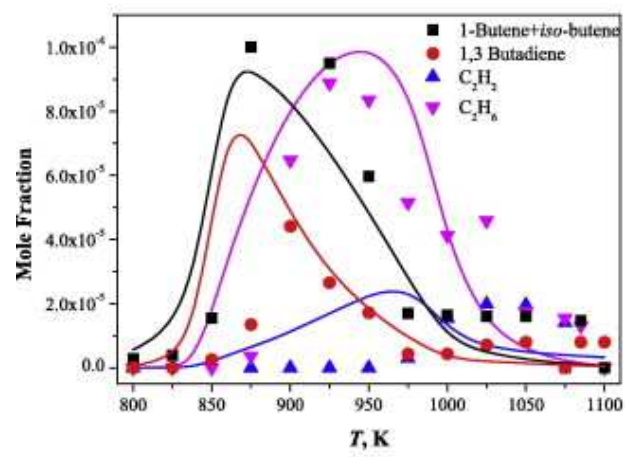

(c)

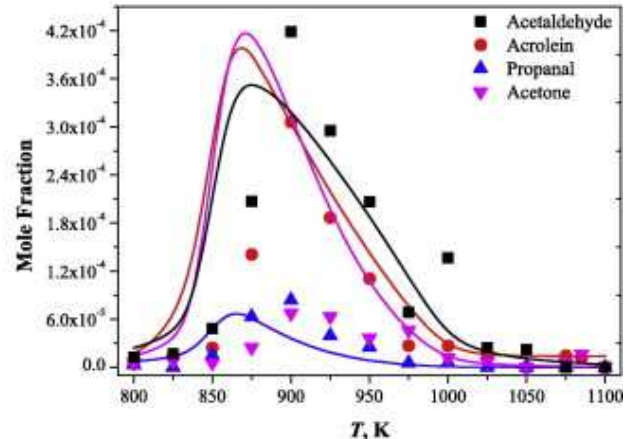

(b)

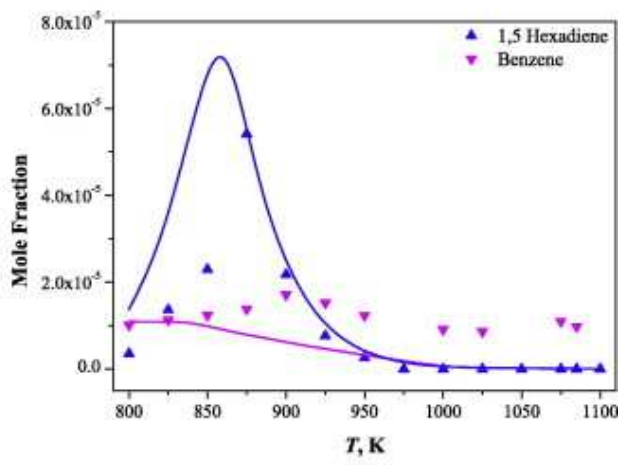

(d)

Figure 15. $1.65 \% \mathrm{C}_{3} \mathrm{H}_{6}, 11.60 \% \mathrm{O}_{2}$ in $\mathrm{He}, \phi=0.64, \mathrm{p}=1.05 \mathrm{~atm}, \tau=2.0 \mathrm{~s}$. Symbols: JSR experimental measurements, lines: current mechanism predictions. 


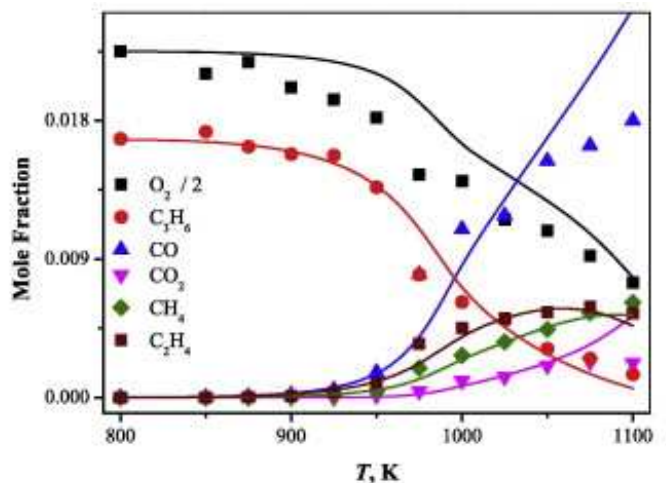

(a)

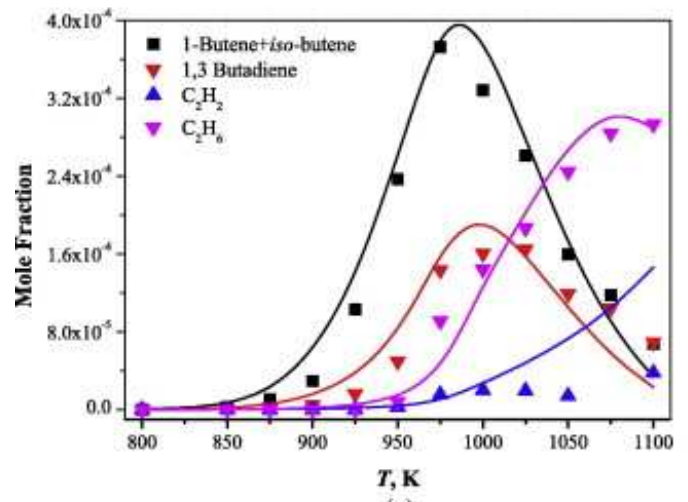

(c)

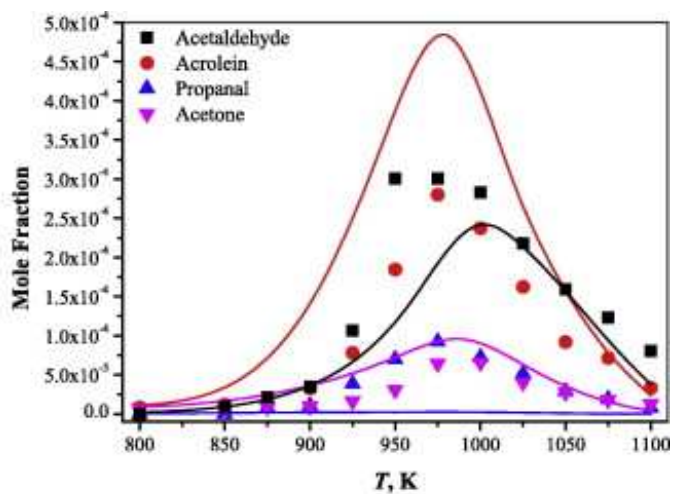

(b)

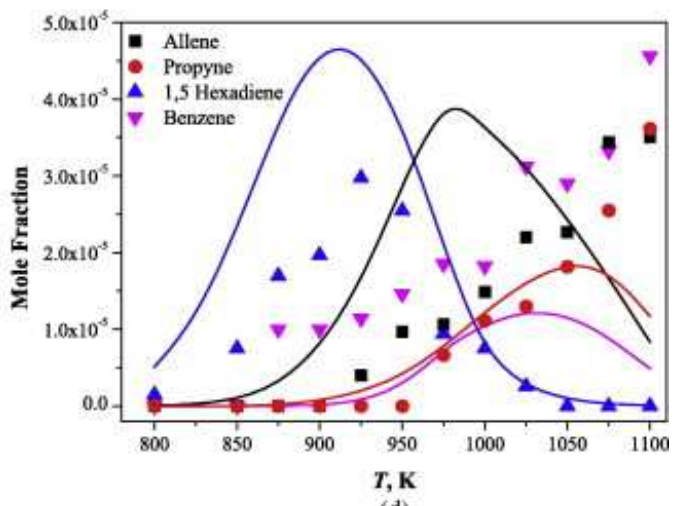

(d)

Figure 16. $1.68 \% \mathrm{C}_{3} \mathrm{H}_{6}, 4.0 \% \mathrm{O}_{2}$ in $\mathrm{He}, \phi=1.68, \mathrm{p}=1.05 \mathrm{~atm}, \tau=2.0 \mathrm{~s}$. Symbols: JSR experimental measurements, lines: current mechanism predictions.

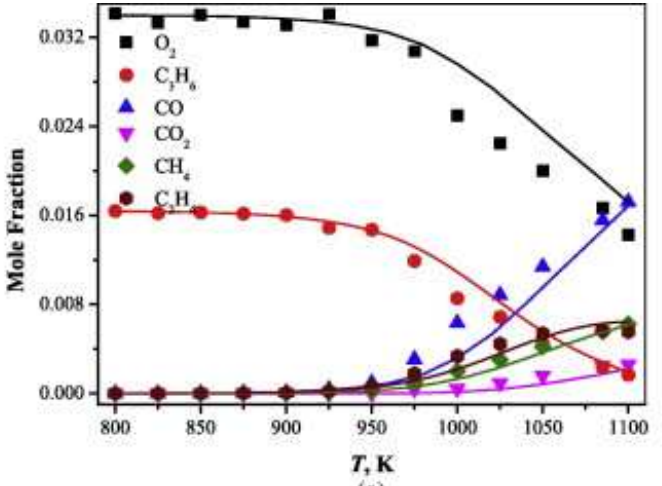

(a)

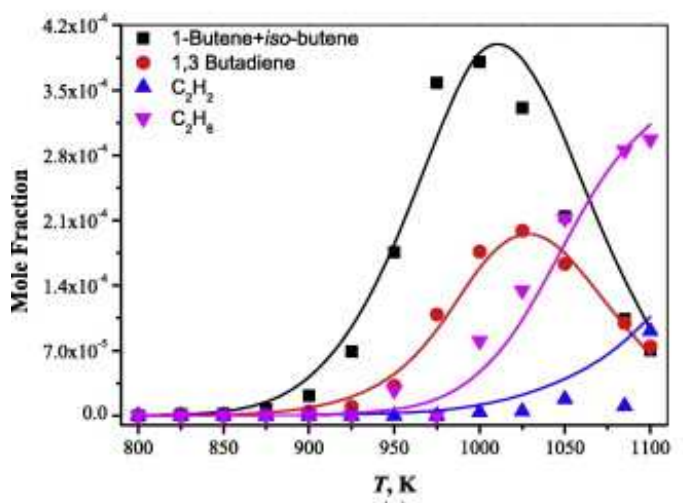

(c)

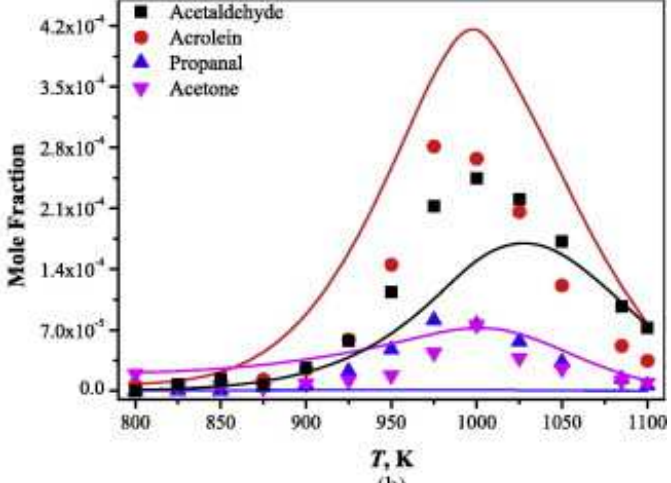

(b)

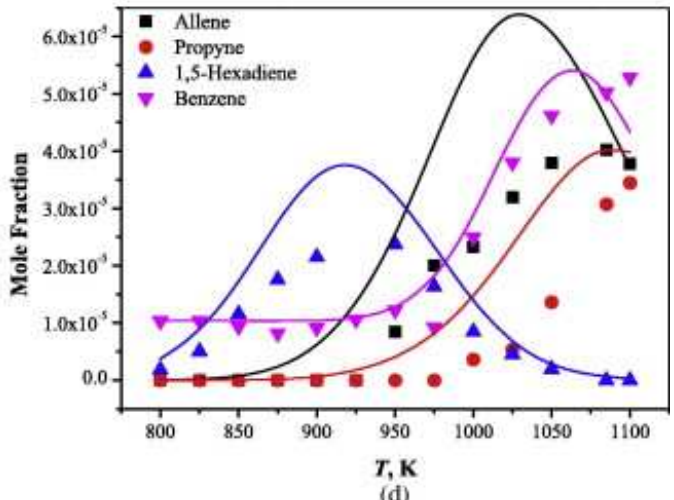

(d)

Figure 17. $1.64 \% \mathrm{C}_{3} \mathrm{H}_{6}, 3.38 \% \mathrm{O}_{2}$ in $\mathrm{He}, \phi=2.19, \mathrm{p}=1.05 \mathrm{~atm}, \tau=2.0$ s. Symbols: JSR experimental measurements, lines: current mechanism predictions. 


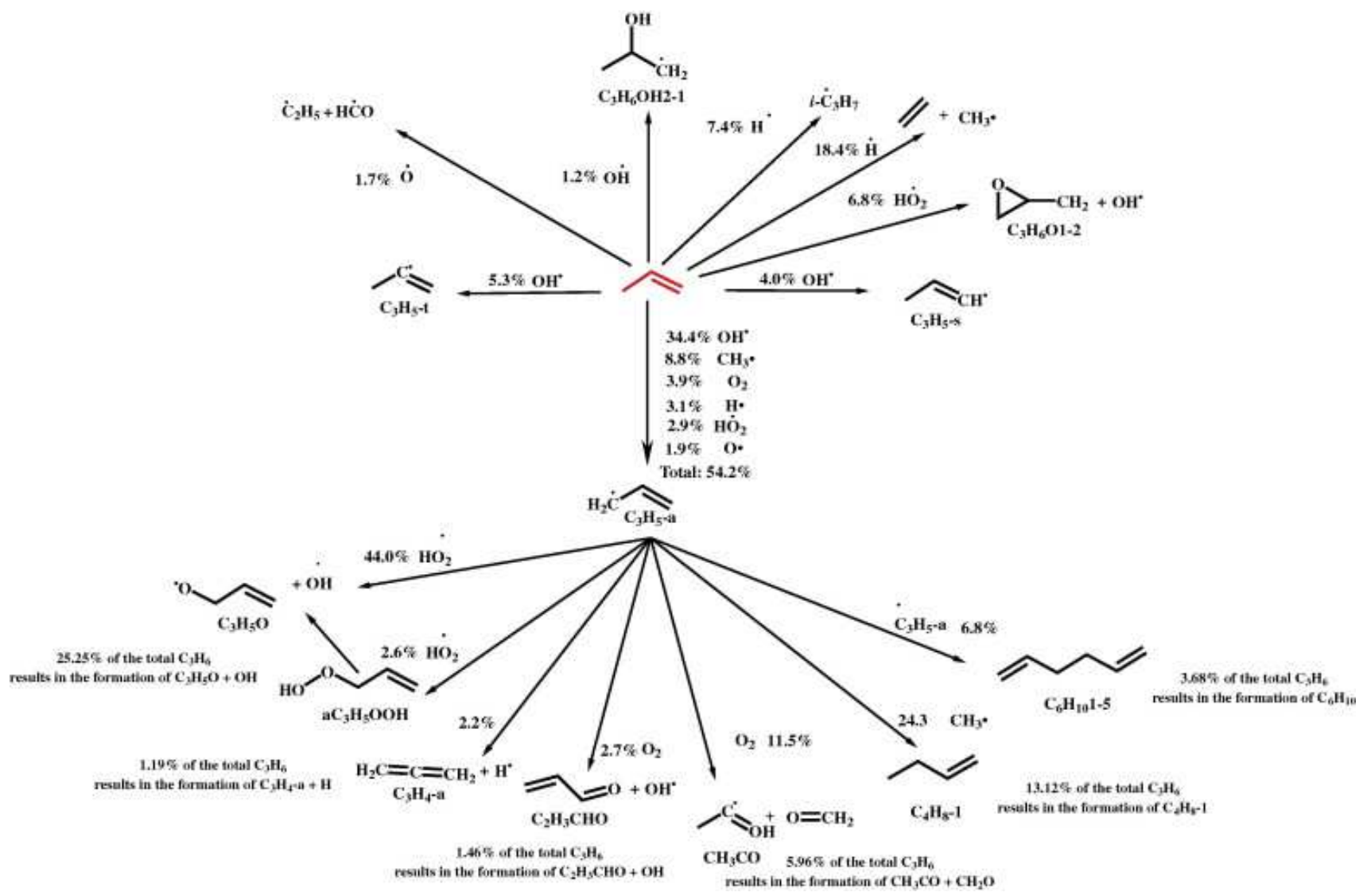

Figure 18. Flux analysis for the oxidation of a mixture of $1.67 \% \mathrm{C}_{3} \mathrm{H}_{6}, 3.38 \% \mathrm{O}_{2}$ diluted in helium, $\phi=2.19$ at $970 \mathrm{~K}$, in a JSR.

\subsubsection{Mechanism performance}

Figures 14 to 17 show the current mechanism's performance against the experimental measurements with generally good agreement between both. Figure 14 shows that reactivity decreases as equivalence ratio increases, and the current mechanism accurately predicts this effect.

To determine the important pathways controlling propene combustion under fuel-rich conditions a flux analysis was carried out and is presented Figure 18.

Hydrogen atom abstraction reactions from propene are important under all conditions in the JSR. Hydrogen atom addition reactions to propene resulting in the formation of stable species such as ethylene and methyl oxirane and methyl, ethyl formyl and iso-propyl radical species were also highlighted as fuel consumption pathways. Propene decomposition reactions were not observed as consumption pathways under the conditions of this study in the JSR.

\subsubsection{Flux analysis for $\phi=2.19$ in the JSR}

The mechanism can accurately predict the oxidation of propene in a JSR under fuel-rich conditions, predicting consumption of the fuel and oxygen and the formation of major intermediate and product species correctly. Figure 18 shows a flux analysis at $970 \mathrm{~K}$ for the fuel-rich mixture in Figure 17 . At this temperature $20 \%$ of the fuel has been consumed. 


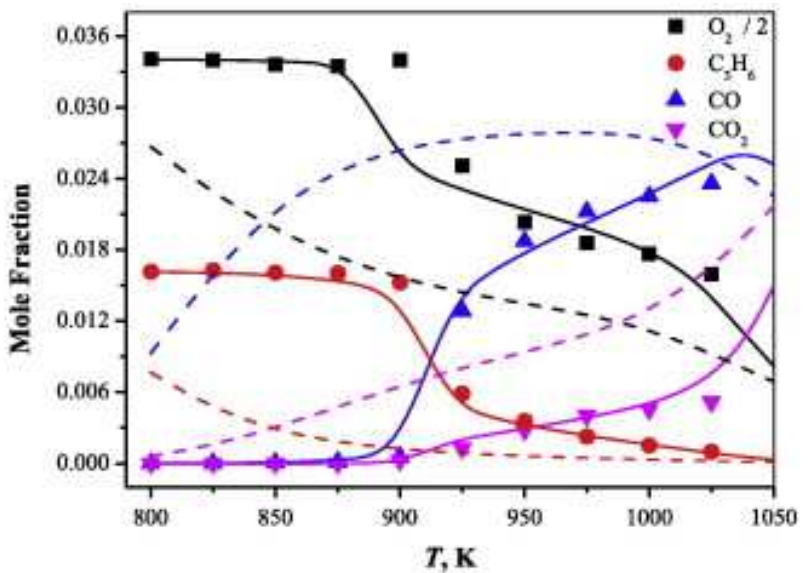

(a)

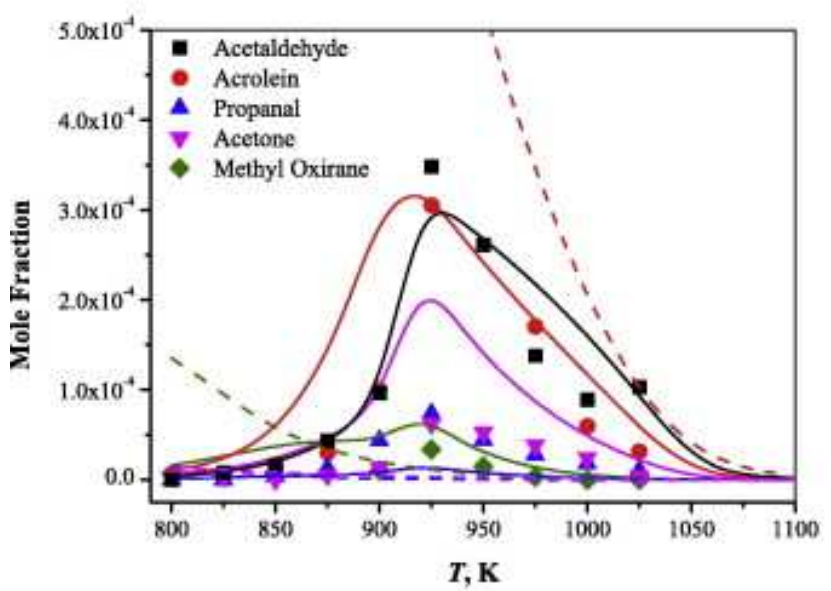

(c)

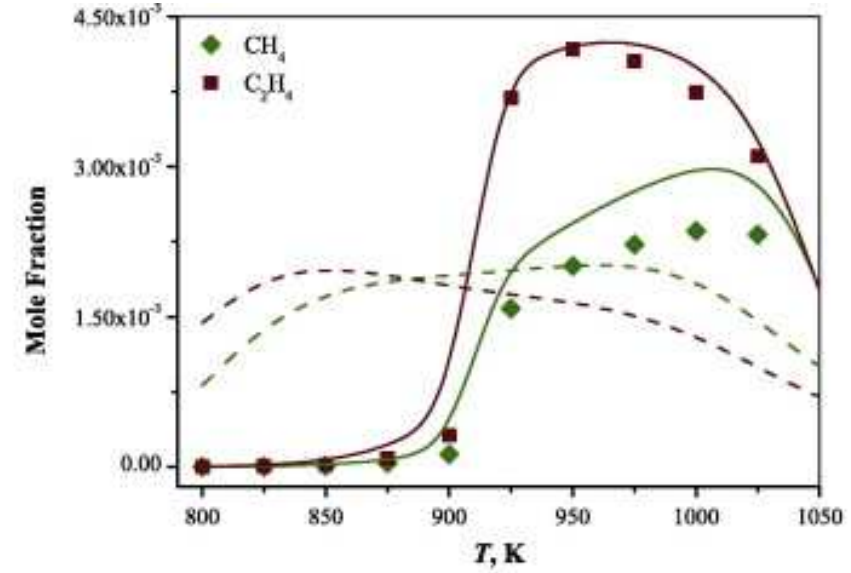

(b)

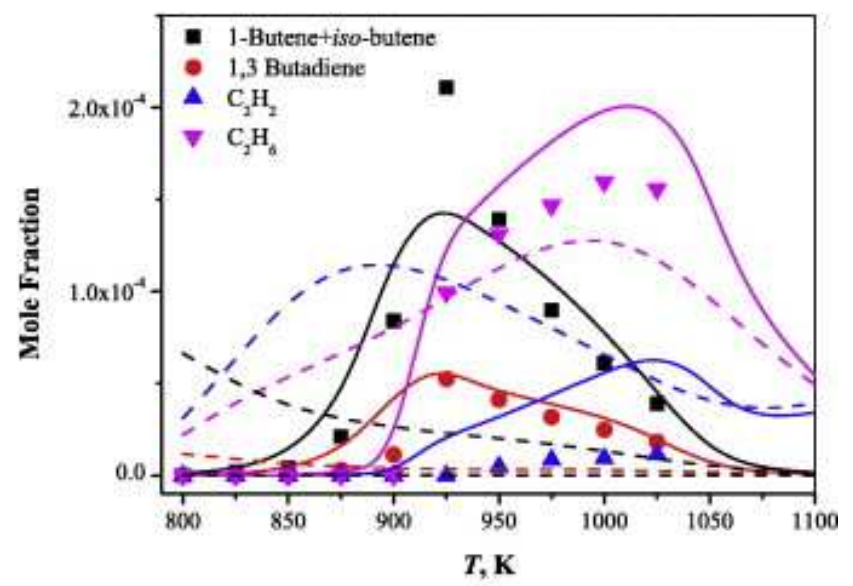

(d)

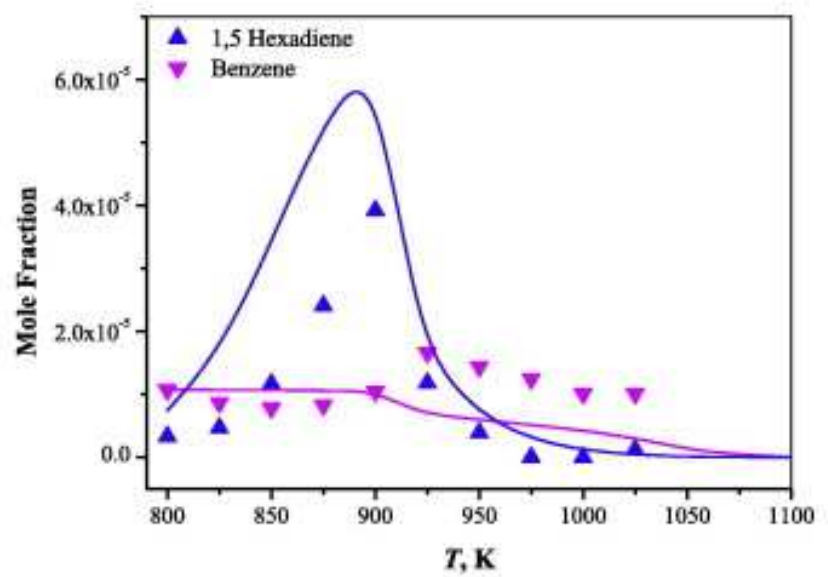

(e)

Figure 19. $1.62 \% \mathrm{C}_{3} \mathrm{H}_{6}, 6.81 \% \mathrm{O} 2$ in $\mathrm{He}, \phi=1.07, \mathrm{p}=1.05 \mathrm{~atm}, \tau=2.0$ s. Symbols: JSR experimental measurements, lines: — current mechanism, - - - AracmoMech 1.3 [31]. 


\subsection{3. $\mathrm{C}_{3} \mathrm{H}_{6}$ consumption}

The main consumption pathways for propene include:

1. Hydrogen atom abstraction to form the $\dot{\mathrm{C}}_{3} \mathrm{H}_{5}-\mathrm{a} \dot{\mathrm{C}}_{3} \mathrm{H}_{5}$-t and $\dot{\mathrm{C}}_{3} \mathrm{H}_{5}-\mathrm{s}$ radicals.

2. Hydrogen atom addition reactions to form $\mathrm{i}-\dot{\mathrm{C}}_{3} \mathrm{H}_{7}$ radical and $\mathrm{C}_{2} \mathrm{H}_{4}+\dot{\mathrm{C}} \mathrm{H}_{3}$.

3. Hydroxyl radical addition to form $\dot{\mathrm{C}}_{3} \mathrm{H}_{6} \mathrm{OH}$ radicals.

4. Hydroperoxyl radical addition to form methyl oxirane.

Radicals such as hydroxyl, hydroperoxyl, methyl, and atomic oxygen all abstract atomic hydrogen from propene. Under the conditions presented in Figure 17, almost half of the propene consumed is converted to allyl radical via hydrogen atom abstraction, also resulting in the formation of $\dot{\mathrm{C}}_{3} \mathrm{H}_{5}-\mathrm{t}(4 \%)$ and $\dot{\mathrm{C}}_{3} \mathrm{H}_{5}-\mathrm{s}(5 \%)$.

Approximately $26 \%$ of propene is consumed via hydrogen atom addition resulting in the formation of ethylene and methyl radical or iso-propyl radical. Other consumption channels include the addition reactions with hydroperoxyl radical yielding methyl-oxirane $\left(\mathrm{C}_{3} \mathrm{H}_{6} \mathrm{O} 1-2\right)$ and hydroxyl radicals forming $\dot{\mathrm{C}}_{3} \mathrm{H}_{6} \mathrm{OH} 2-1$ radical.

\subsection{4. $\dot{\mathrm{C}}_{3} \mathrm{H}_{5}$-a consumption}

The main consumption pathways for allyl radical include:

1. Reaction with hydroperoxyl radical to form $\mathrm{C}_{3} \mathrm{H}_{5} \mathrm{O}$, and $\mathrm{aC}_{3} \mathrm{H}_{5} \mathrm{OOH}$.

2. Recombination reaction with methyl radical to form $\mathrm{C}_{4} \mathrm{H}_{8}-1$.

3. Reaction with molecular oxygen to form vinoxy radical and formaldehyde or acrolein and hydroxyl radical.

4. Recombination reaction with itself to form $\mathrm{C}_{6} \mathrm{H}_{10} 1-5$.

Over $45 \%$ of allyl radicals react with hydroperoxyl radicals. This can result in the formation of allyloxy radicals $\left(\mathrm{C}_{3} \mathrm{H}_{5} \mathrm{O}\right)$ and hydroxyl radicals $(44 \%)$ or can result in the formation of allyl hydroperoxide $\left(\mathrm{aC}_{3} \mathrm{H}_{5} \mathrm{OOH}\right)(2.6 \%)$ which subsequently decomposes to form allyloxy and hydroxyl radicals. Allyloxy radical undergoes isomerization reactions to form formyl-ethyl radical $\left(\mathrm{C}_{2} \mathrm{CH}_{2} \mathrm{CHO}\right)$ or vinoxyl-methyl radicals $\left(\mathrm{C}_{2} \mathrm{H}_{3} \mathrm{O} \mathrm{C}_{2}\right)$ or can decompose to give acrolein and atomic hydrogen or ethylene and a formyl radical. In addition to reactions with $\mathrm{HO}_{2}$, allyl radical can undergo radical-radical recombination reactions with itself or with methyl radicals to produce 1,5 -hexadiene $(6.8 \%)$ or 1 -butene $(24.8 \%)$ respectively. The mechanism predicts that these recombination reactions are the main source of both $\mathrm{C}_{6} \mathrm{H}_{10}$ and $\mathrm{C}_{4} \mathrm{H}_{8}$ detected in the JSR. Allyl radical can also undergo reactions with molecular oxygen to form vinoxy radical and formaldehyde or acrolein and hydroxyl radical or can decompose to form allene and atomic hydrogen.

\subsection{5. $\dot{\mathrm{C}}_{3} \mathrm{H}_{5}-\mathrm{S}$ and $\dot{\mathrm{C}}_{3} \mathrm{H}_{5}$-t consumption}

The other $\dot{\mathrm{C}}_{3} \mathrm{H}_{5}$ radicals, 2-propenyl $\left(\dot{\mathrm{C}}_{3} \mathrm{H}_{5}-\mathrm{t}\right)$ and 1-propenyl $\left(\dot{\mathrm{C}}_{3} \mathrm{H}_{5}-\mathrm{s}\right)$, mainly react with molecular oxygen. $\dot{\mathrm{C}}_{3} \mathrm{H}_{5}-$ $\mathrm{t}+\mathrm{O}_{2}$ resulting in the formation of formaldehyde and acetyl radical (49.7\%) or atomic oxygen and acetonyl radical (48.7\%). The reaction of $\dot{\mathrm{C}}_{3} \mathrm{H}_{5}-\mathrm{S}+\mathrm{O}_{2}$ forms acetaldehyde and formyl radical (61.2\%), acrolein and hydroxyl radical (16.8\%), or $\mathrm{CH}_{3} \dot{\mathrm{C}} \mathrm{HCHO}$ radical and atomic oxygen (3.4\%). The reaction of 1-propenyl radical and molecular oxygen is predicted to be the main source of acetaldehyde in the JSR. The decomposition of $\dot{\mathrm{C}}_{3} \mathrm{H}_{5}-\mathrm{s}$ to acetylene and methyl radical accounts for almost $18 \%$ of 1-propenyl radical consumption and is predicted to be the main source of acetylene in the JSR. 


\subsubsection{Mechanism performance}

Figures 15, 16 and 19 show species profiles for propene oxidation in a JSR at $\phi=0.64,1.68$, and 1.07 respectively. The experimental measurements are compared to predictions from the current mechanism, which is able to predict the profiles for fuel and oxygen consumption and also predicts the main intermediate and product species profiles. The mechanism over-predicts the concentration of acetylene across the range of equivalence ratios. Approximately $20 \mathrm{ppm}$ of acetylene is formed in the JSR at $\phi=1.68$ at $1000 \mathrm{~K}$, but the mechanism predicts approximately $50 \mathrm{ppm}$. The mechanism consistently under-predicts the concentrations of benzene at $\phi \leqslant 1.68$, and propanal at $\phi=1.07-2.19$. Currently, the reason behind the under-prediction of benzene yields is unknown. The propargyl radical formed does not undergo recombination to form benzene but reacts with molecular oxygen. Under fuel-rich conditions as shown in Figure 17 benzene is formed via the $\dot{\mathrm{C}}_{3} \mathrm{H}_{5}-\mathrm{a}+\dot{\mathrm{C}}_{3} \mathrm{H}_{3} \rightarrow \mathrm{C}_{6} \mathrm{H}_{6}+\dot{\mathrm{H}}+\dot{\mathrm{H}}$ reaction, however this is not a dominant reaction pathway under fuel-lean conditions. The causes of the under-prediction of propanal is also unclear. In general propanal comes from $\dot{\mathrm{C}}_{3} \mathrm{H}_{6} \mathrm{OH} 1-2+\mathrm{O}_{2} \leftrightarrow \mathrm{C}_{2} \mathrm{H}_{5} \mathrm{CHO}+\mathrm{HO}_{2}$ and $\mathrm{C}_{2} \mathrm{H}_{5} \mathrm{CHO}+\dot{\mathrm{H}} \leftrightarrow \dot{\mathrm{C}}_{3} \mathrm{H}_{6} \mathrm{OH} 1-2$ and acetone comes from the reactions $\mathrm{CH}_{3} \mathrm{COCH}_{3}+\dot{\mathrm{H}} \leftrightarrow \dot{\mathrm{C}}_{3} \mathrm{H}_{6} \mathrm{OH} 2-1$ and $\dot{\mathrm{C}}_{3} \mathrm{H}_{6} \mathrm{OH} 2-1+\mathrm{O}_{2} \leftrightarrow \mathrm{CH}_{3} \mathrm{COCH}_{3}+\mathrm{HO}_{2}$. The $\dot{\mathrm{C}}_{3} \mathrm{H}_{6} \mathrm{OH}$ radicals are formed via ÖH addition to $\mathrm{C}_{3} \mathrm{H}_{6}$. These rate constants were adopted from Zádor et al. [47]. Their recommendation of a 50:50 ratio of terminal to central addition has been altered to a 75:25 ratio in order to reduce the over-prediction of acetone and under-prediction of propanal. As shown in Figs. 16, 17 and 19 this alteration was not sufficient. Further alteration of the current 75:25 ratio is not supported in the current literature. Acrolein is overpredicted at $\varphi=1.68$ and 2.19. Acrolein is almost exclusively produced from the $\dot{\mathrm{C}}_{3} \mathrm{H}_{5}-\mathrm{a}+\mathrm{HO}_{2}$ system; rate constants for these reactions have been adopted from the study of Goldsmith et al. [56]. At this time we are unsure of the causes of the over-prediction under fuel-rich conditions.

There is good agreement between the experimental measurements and the current mechanism at $\phi=2.19$. As shown in Figure 14, reactivity decreases going from fuel-lean to fuel-rich mixtures. After $2.0 \mathrm{~s}$, approximately $20 \%$ of the propene consumption occurs at $1000 \mathrm{~K}$ for the $\phi=2.19$ mixture, while $20 \%$ consumption occurs at approximately $875 \mathrm{~K}$ for the $\phi=0.64$ mixture. The mechanism can accurately predict this shift in reactivity as a function of equivalence ratio. The mechanism predicts an increased influence of chain terminating reactions, thereby reducing the overall reactivity under fuel-rich conditions.

\subsubsection{Comparison with the previous mechanism's performance}

Figure 19 shows the results of the improved chemical kinetic scheme in comparison with the performance of AramcoMech 1.3 against the experimental measurements at $\phi=1.07$. The previous mechanism overpredicted reactivity and predicted reactivity at a significantly lower temperature than the current mechanism. At $800 \mathrm{~K}$, the current mechanism predicts $<1 \%$ fuel consumption while the previous mechanism predicts $53 \%$ consumption. The current mechanism can accurately predict the profiles of many of the intermediate species, such as methane, ethylene, acetaldehyde, acrolein, butene, 1,3-butadiene, and 1,5-hexadiene, while AramcoMech 1.3 could not. The changes from the previous to the current mechanism that had the largest effect on the mechanism performance in the JSR include: the updated rate constants for $\mathrm{C}_{3} \mathrm{H}_{6}+\mathrm{OH}$, the inclusion of rate constants for the $\mathrm{C}_{3} \mathrm{H}_{5}-\mathrm{a}+\mathrm{HO}_{2}$ system, and $\mathrm{C}_{3} \mathrm{H}_{5}-\mathrm{a}+\mathrm{C}_{3} \mathrm{H}_{5}$-a recombination.

\subsection{Flow reactor results}

Experiments for propene oxidation have been performed at Princeton University in two flow reactors: the Variable Pressure Flow Reactor (VPFR) and the High Pressure Laminar Flow Reactor (HPLFR). Experiments were 
conducted at elevated pressures, low and intermediate temperatures, over a range of equivalence ratios as a function of residence time.

\subsubsection{Variable Pressure Flow Reactor (VPFR)}

Propene oxidation was studied experimentally in the VPFR over a pressure range of 8-12.5 atm and in the temperature range $612-1047 \mathrm{~K}$. The VPFR can be simulated using a constant pressure adiabatic assumption and relative time shift between simulation and experimental time [27]. In this study the mechanism is shifted to match approximately 50\% fuel consumption. There is good agreement between the mechanism and the experimental measurements across the range of pressures, temperatures, and equivalence ratios, Figures 20 and 21. Additional plots for other experimental conditions are included in Supplementary Material.

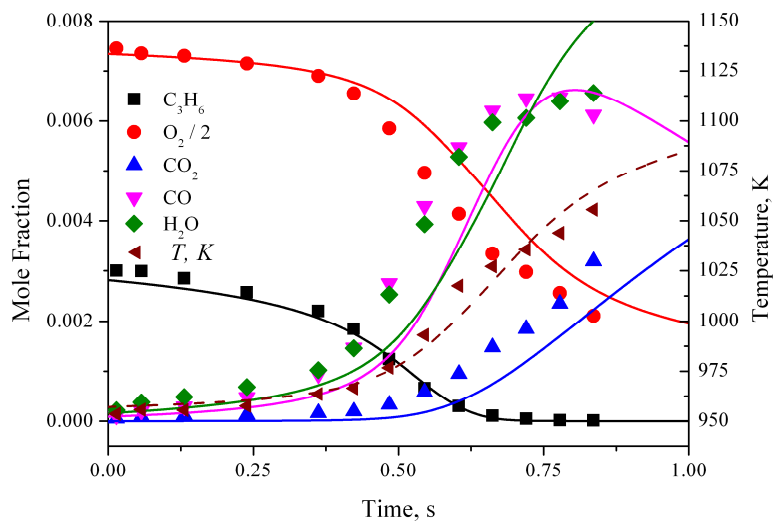

(a)

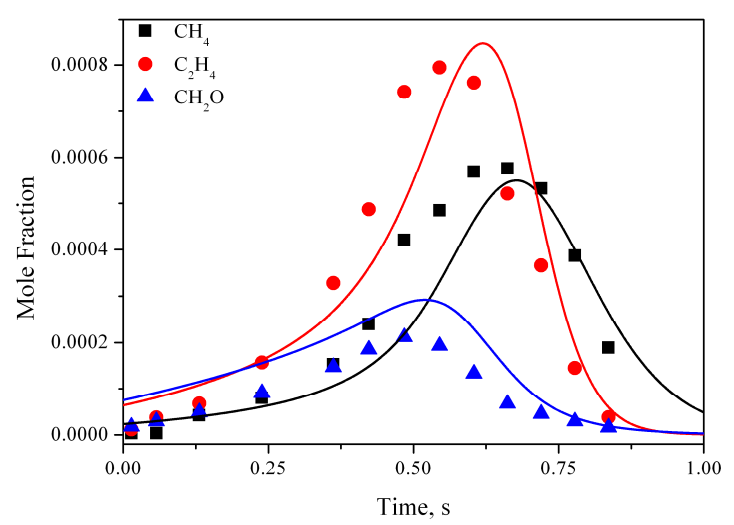

(b)

Figure 20. $0.31 \% \mathrm{C}_{3} \mathrm{H}_{6}, 1.149 \% \mathrm{O}_{2}$ in $\mathrm{N}_{2}, \phi=0.94, \mathrm{p}=8 \mathrm{~atm}, \mathrm{~T}=955 \mathrm{~K}$. Symbols: VPFR experimental measurements, lines: current mechanism predictions, time shift: $-0.38 \mathrm{~s}$.

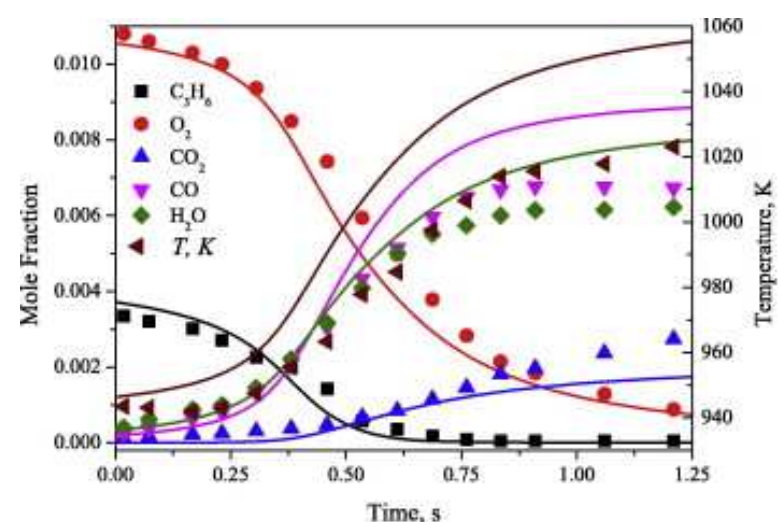

(a)

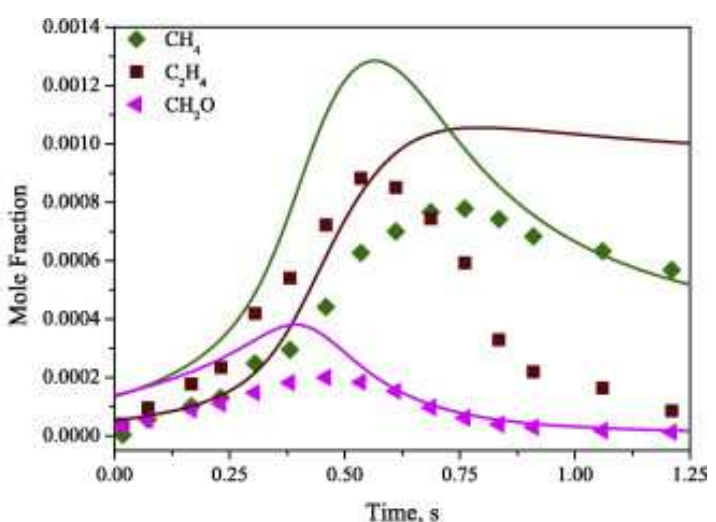

(b)

Figure 21. $0.34 \% \mathrm{C}_{3} \mathrm{H}_{6}, 1.1 \% \mathrm{O}_{2}$ in $\mathrm{N}_{2}, \phi=1.37, \mathrm{p}=10 \mathrm{~atm}, \mathrm{~T}=942 \mathrm{~K}$. Symbols: VPFR experimental measurements, lines: current mechanism predictions, time shift: $-0.62 \mathrm{~s}$.

\subsubsection{Previous mechanism performance}

A comparison of the performance of the current mechanism and AramcoMech 1.3 [32] is shown in Figure 22. The conditions in this example are: $\phi=0.70$ mixture at a pressure of $12.5 \mathrm{~atm}$ and initial reaction temperature 
of $843 \mathrm{~K}$. Unlike the predictions of the current mechanism, the simulations for the previous mechanism could not be meaningfully time shifted to agree with the experimental measurements; for this reason the AramcoMech 1.3 predictions are not time shifted. The required positive time shift for the AramcoMech 1.3 predictions (relative to the experimental timeframe) is contrary to the physics of the preheated, non-premixed VPFR reacting flowfield, which tends to reduce chemical induction times relative to idealized reacting plug flow conditions. This reduced induction time amounts to a negative time shift from ideal time zero, which should be qualitatively matched by a negative time shift for modeling predictions. See Ref. [27] for further discussion of this issue.

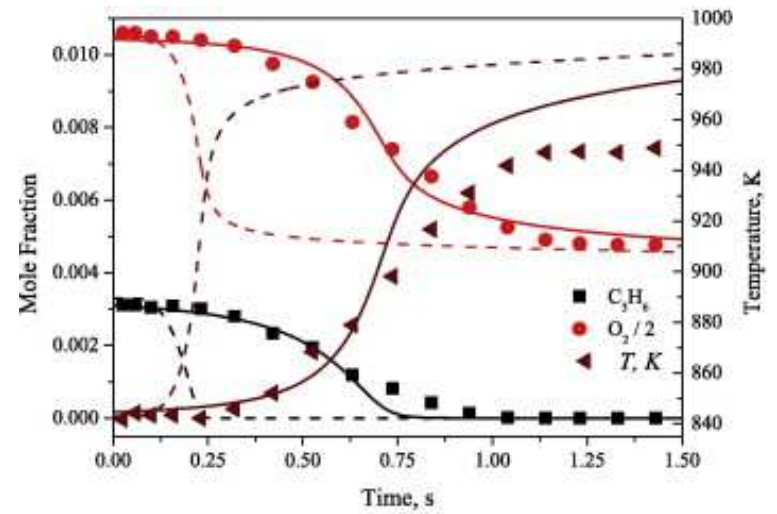

(a)

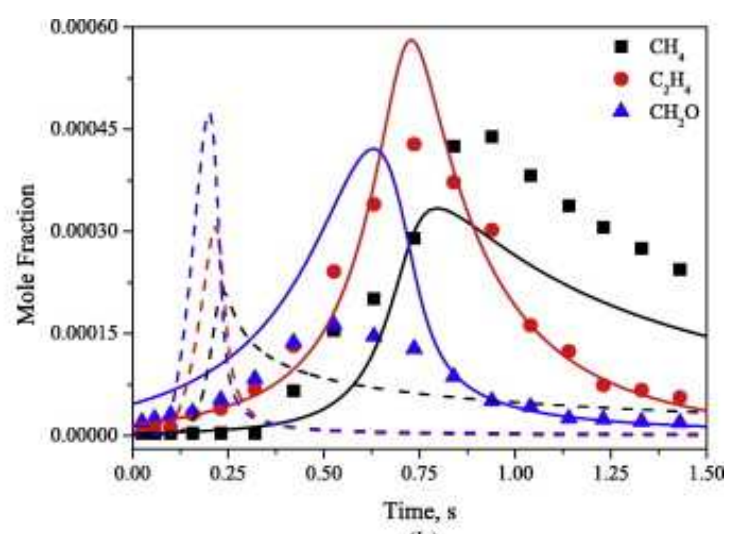

(b)

Figure 22. $0.33 \% \mathrm{C}_{3} \mathrm{H}_{6}, 2.10 \% \mathrm{O}_{2}$ in $\mathrm{N}_{2}, \phi=0.70, \mathrm{p}=12.5 \mathrm{~atm}, \mathrm{~T}=843 \mathrm{~K}$. Symbols: VPFR experimental measurements, Lines: — current mechanism (time shift: $-0.75 \mathrm{~s}$ ), - - - AramcoMech 1.3 [32] (no time shift).

In comparison to AramcoMech 1.3, in the current mechanism less of the allyl radical is consumed by reaction with hydroperoxyl radical and more is consumed via chain terminating reactions such as self-recombination to form 1,5-hexadiene. Therefore the current mechanism is less reactive compared to AramcoMech 1.3.

\subsubsection{High Pressure Laminar Flow Reactor (HPLFR)}

Propene oxidation experiments conducted in the HPLFR were at a fixed pressure of $15.0 \pm 0.1 \mathrm{~atm}$. For each of the four HPLFR experiments reported here, the measured axial temperature profile of the flow prior to addition of oxidizer was a constant $800 \pm 5 \mathrm{~K}$ along the test section. Upon addition of $\mathrm{O}_{2}$ to the $\mathrm{C}_{3} \mathrm{H}_{6} / \mathrm{N}_{2}$ mixture, the measured temperature increase from the $800 \mathrm{~K}$ baseline was less than $+20 \mathrm{~K}$ for fuel-lean experiments, and less than $+5 \mathrm{~K}$ for the stoichiometric and fuel-rich cases. For this reason the experiments are defined as near-isothermal. Initial fuel mole fractions ranged from 4000 to $6250 \mathrm{ppm}$ for equivalence ratios of $\phi=0.35$, $0.5,1.0$, and 1.25. These experiments have been simulated using an isothermal assumption. The mechanism was time shifted in order to best match the propene concentration at fuel-lean conditions, ( Figure 23), and to match the water concentration for the stoichiometric and fuel-rich conditions, ( Figures 24 and 25), since the measured water profile has the highest gradient relative to its measurement uncertainty (i.e., it is the most sensitive measurement). 


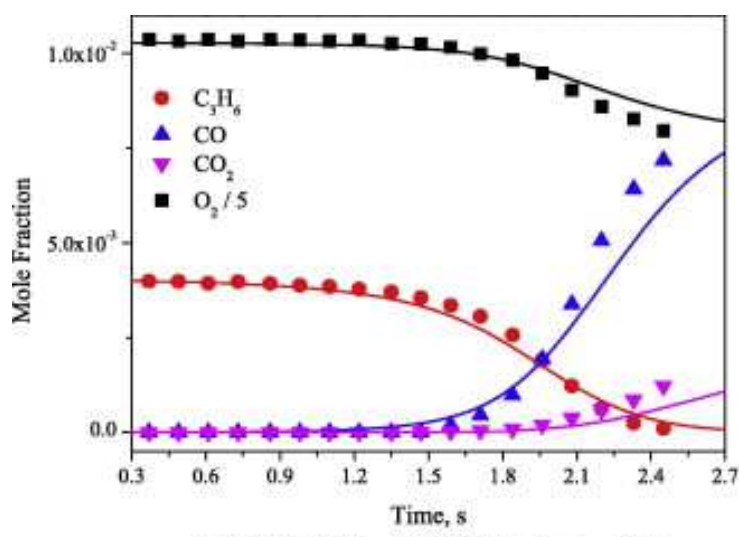

(a) $0.40 \% \mathrm{C}_{3} \mathrm{H}_{6}, 5.14 \% \mathrm{O}_{2}$ in $\mathrm{N}_{2}, \varphi=0.35$

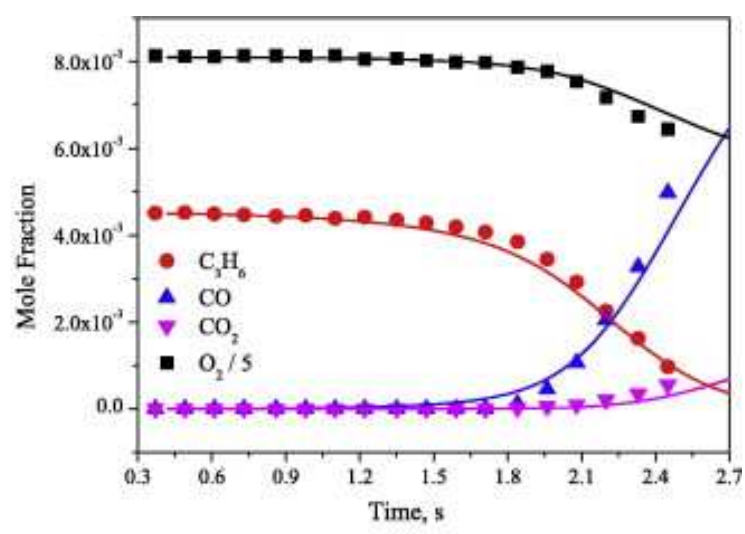

(b) $0.45 \% \mathrm{C}_{3} \mathrm{H}_{6}, 4.05 \% \mathrm{O}_{2}$ in $\mathrm{N}_{2}, \varphi=0.5$

Figure 23. Symbols: HPLFR experimental measurements $p=15 \mathrm{~atm}, T=800 \mathrm{~K}$, lines: current mechanism predictions, time shifted by $0.28 \mathrm{~s}$ and 0.42 to match $\mathrm{C}_{3} \mathrm{H}_{6}$ mole fractions for figures (a) and (b), respectively.

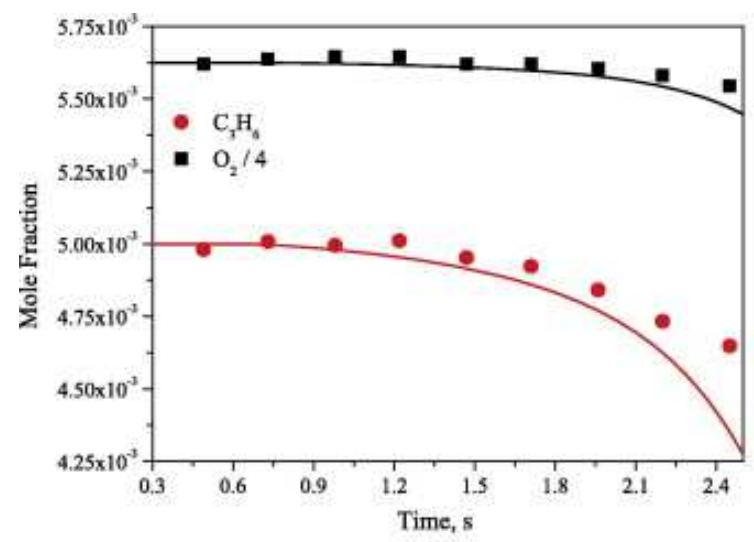

(a)

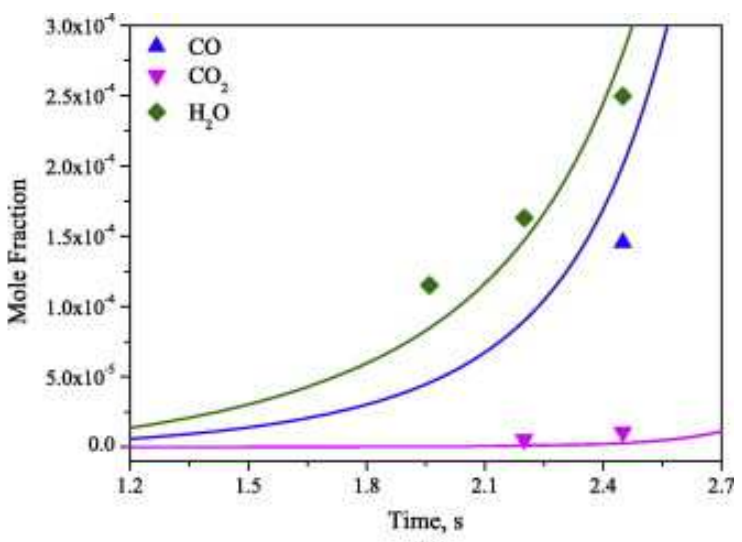

(b)

Figure 24. $0.50 \% \mathrm{C}_{3} \mathrm{H}_{6}, 2.25 \% \mathrm{O}_{2}$ in $\mathrm{N}_{2}, \phi=1.00, \mathrm{p}=15 \mathrm{~atm}, \mathrm{~T}=800 \mathrm{~K}$. Symbols: HPLFR experimental measurements, lines: mechanism predictions, time shifted (0.65 s) to match $\mathrm{H}_{2} \mathrm{O}$ profile.

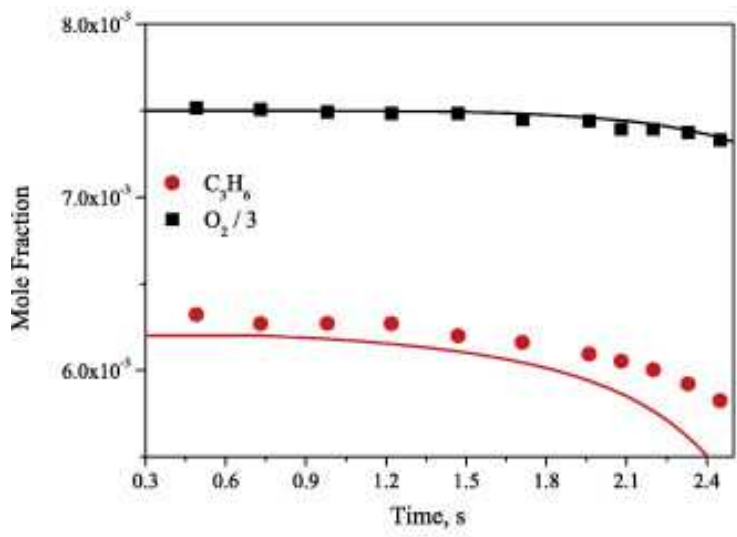

(a)

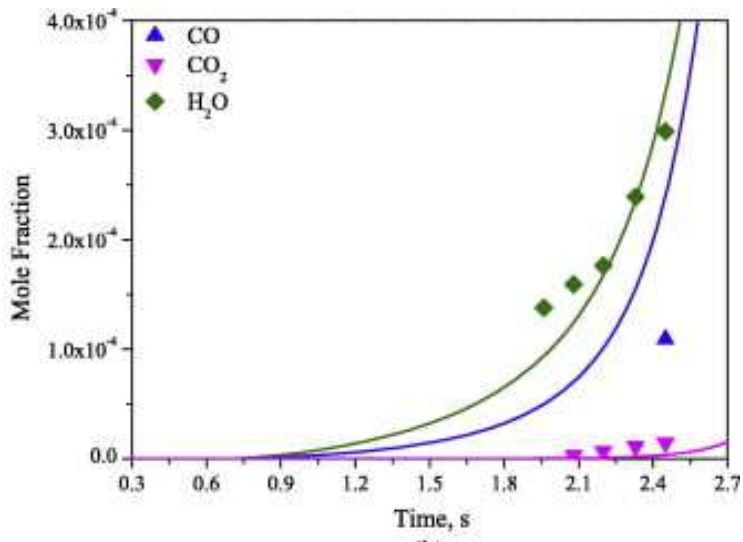

(b)

Figure 25. $0.62 \% \mathrm{C}_{3} \mathrm{H}_{6}, 2.25 \% \mathrm{O}_{2}$ in $\mathrm{N}_{2}, \phi=1.25, \mathrm{p}=15 \mathrm{~atm}, \mathrm{~T}=800 \mathrm{~K}$. Symbols: HPLFR experimental measurements, lines: current mechanism predictions, time shifted $(0.70 \mathrm{~s})$ to match $\mathrm{H}_{2} \mathrm{O}$ profile. 


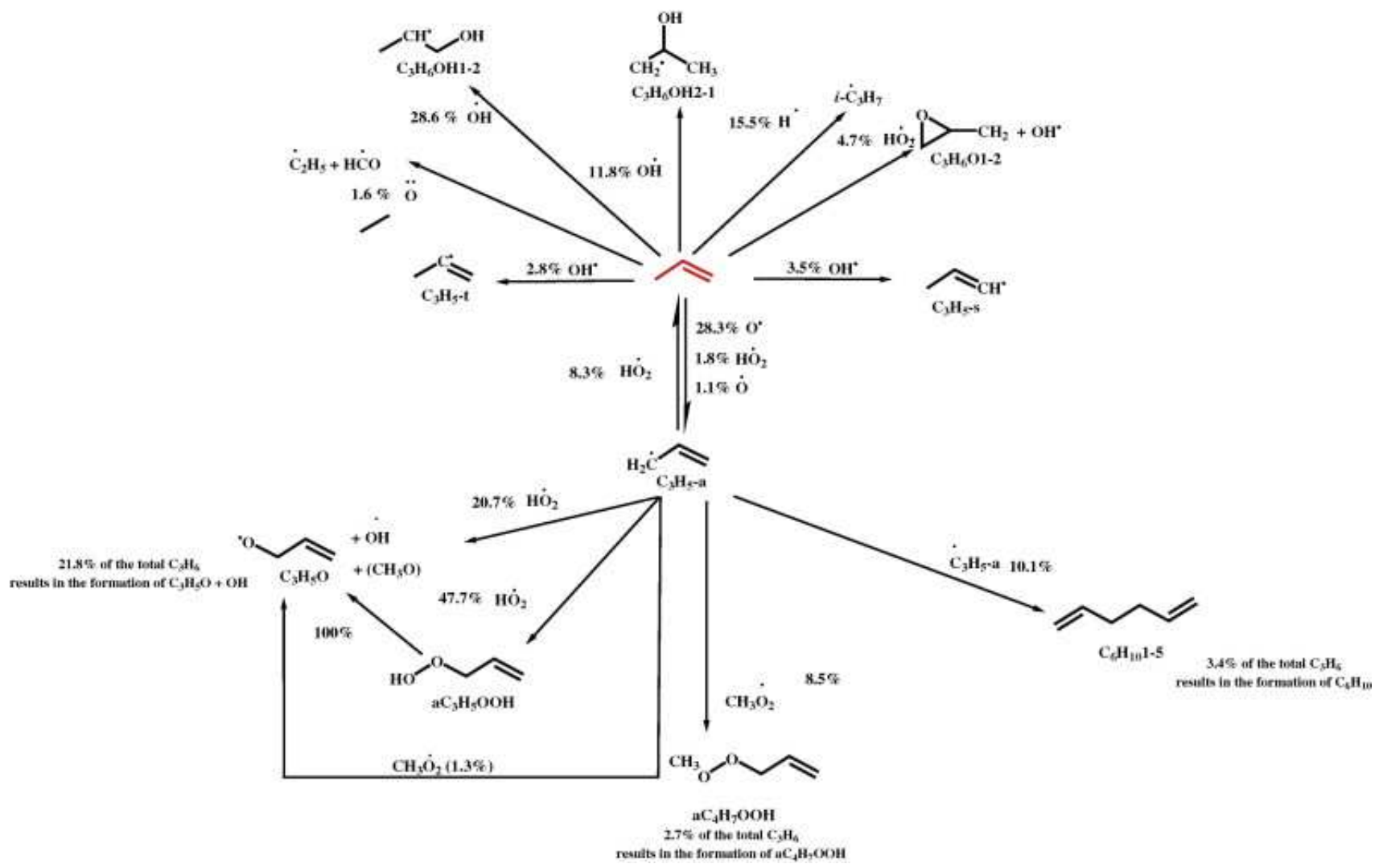

Figure 26. Flux analysis for the oxidation of a mixture of $0.40 \% \mathrm{C}_{3} \mathrm{H}_{6}, 5.14 \% \mathrm{O}_{2}$ in $\mathrm{N}_{2}, \phi=0.35, p=15.0$ atm, $\mathrm{T}$ $=800 \mathrm{~K}$ mixture after $1.3 \mathrm{~s}$, at HPLFR conditions.

In addition to the species reported in Figures 23 to 25, the gas chromatograph (GC) was calibrated to measure $\mathrm{H}_{2}, \mathrm{CH}_{4}, \mathrm{C}_{2} \mathrm{H}_{6}$, allene, and propyne but the mole fractions of these species were below detection/quantification limits of the experiments. Water and formaldehyde profiles have been omitted from the fuel-lean measurements due to sample condensation observed during the experiments.

\subsubsection{Mechanism performance}

Overall there is good agreement between the mechanism predictions and the HPLFR experimental measurements. The stoichiometric and fuel-rich mixtures show very little reactivity, Figures 24 and 25 respectively. Less than $7 \%$ of the fuel is consumed by the end of the experiment for the stoichiometric mixture, Figure 24 , and less than $8 \%$ is consumed in the $\phi=1.25$ mixture, Figure 25.

\subsubsection{Flux analysis for $\phi=0.35, p=15$ atm in the HPLFR}

A flux analysis for a $\phi=0.35$ mixture at $1.3 \mathrm{~s}$ is included in Figure 26 to provide an overview of propene combustion and the pathways that form intermediate and product species at HPLFR conditions. At $1.3 \mathrm{~s}, 20 \%$ of the fuel has been consumed by a variety of radical abstraction, addition, and metathesis reactions. Unlike $\mathrm{C}_{3} \mathrm{H}_{5}$-a formation at JSR conditions of Figure 18, no one intermediate production channel dominates fuel consumption. 
Many of the reactions are similar to the analysis carried out for the JSR in Figure 18. However, under the elevated pressures in the HPLFR a higher percentage of the $\mathrm{C}_{3} \mathrm{H}_{5}$-a is consumed via self-recombination to form 1,5-hexadiene (10.1\%) in comparison to the near-atmospheric pressure experiments studied in the JSR (6.8\%) as in Figure 18. Under this condition of temperature and pressure, hydroxyl radical addition to propene to form the two $\dot{\mathrm{C}}_{3} \mathrm{H}_{7} \mathrm{O}$ radicals $\left(\dot{\mathrm{C}}_{3} \mathrm{H}_{6} \mathrm{OH} 1-2\right.$ and $\left.\dot{\mathrm{C}}_{3} \mathrm{H}_{6} \mathrm{OH} 2-1\right)$ and consumes a significant percentage of the fuel (40\%). These radicals react with molecular oxygen to form propanal and acetone respectively. The reaction between allyl and methyl-peroxy radical is identified as a consumption pathway for allyl radical. Methyl-peroxy radical is formed via the pressure dependent reaction of methyl radical and molecular oxygen.

\section{Conclusions}

A new chemical kinetic mechanism has been developed to describe the combustion of propene. Important reactions were identified through sensitivity and flux analyses. Rate constants have been adopted from the most comprehensive experimental and theoretical studies where possible. However, for reactions where the literature is lacking, rate constants were estimated. This study includes new estimated rate constants for the reactions of molecular oxygen with propene and with 1- and 2-propenyl radicals. Due to the importance of the reactions of propene and 1- and 2-propenyl radicals with molecular oxygen, further study is recommended. This mechanism has been validated over a wide range of conditions ( $T, p, \phi$, and $\%$ dilution) and shows good agreement with experimental measurements from jet-stirred and flow reactors.

The chemical kinetic mechanism has shown significant improvement over a previous version of the mechanism that was validated for $\mathrm{C}_{1}-\mathrm{C}_{2}$ chemistry only [32]. This study highlights the importance of only using a chemical kinetic mechanism within its validation limits and offers a contribution to our understanding of small molecule oxidation. The propene sub-mechanism presented herein is intrinsically linked with the $C_{2}$ mechanism and vice versa. The effect of the current mechanism on $C_{1}-C_{2}$ targets is shown in Supplementary Material and a discussion is included where significant differences exist between the performance of AramcoMech 1.3 and the current mechanism.

New experimental measurements for propene oxidation in the JSR at a pressure near 1 atm over an equivalence ratio range of $\phi=0.64-2.19$ are reported. These measurements were obtained at lower temperatures than previously investigated. Some challenges remain with the mechanism performance, as the current kinetic scheme consistently results in the over-prediction of acetone and acetylene and underprediction of propanal, and benzene formed. The mechanism will be developed and improved as further experimental and theoretical data becomes available in order to enhance performance for these species.

Speciation profiles were measured in two different flow reactors: the Princeton VPFR and the HPLFR. Data from the VPFR were obtained over the temperature range 843-1047 $\mathrm{K}$ and the pressure range 6-12.5 atm for varying equivalence ratios. The data from the HPLFR were obtained at $800 \mathrm{~K}$ and $15 \mathrm{~atm}$ over a range of equivalence ratios under nearly isothermal flow conditions. HPLFR experiments show that propene exhibits very little reactivity at $800 \mathrm{~K}$ and $\mathrm{p}=15 \mathrm{~atm}$ for $\phi=1.0$ and 1.25 mixtures. The mechanism can accurately predict fuel and oxygen consumption as well as product formation for both flow reactors.

Tabulated JSR, VPFR, and HPLFR experimental data are included as Supplementary Material. Also included is a comparison of the performance of the current mechanism against the experimental data presented in this study and in Part II [10] and from the literature [3-5,17,77], as well as the performance of literature mechanisms $[5,11,32]$.

Part II of this study [10] presents ignition delay time measurements for propene over a pressure range of 2$40 \mathrm{~atm}$, temperature range of $750-1750 \mathrm{~K}$ and for equivalence ratios of $\phi=0.5-2.0$. Propene flame speed and 
mass burning rate measurements are also presented in Part II. The ignition and flame data are compared with the chemical kinetic mechanism presented in Part I.

\section{Acknowledgments}

Work at Princeton University was supported by the U.S. Department of Energy, Office of Science, Office of Basic Energy Science, both as part of the Combustion Energy Frontier Research Center, an Energy Frontier Research Center funded under award number DE-SC0001198, as well as under award number DE-FG0286ER13503 administered by the Chemical Sciences, Geosciences, and Biosciences Division. The authors also thank Ms. Lily Zheng for assistance in performing VPFR experiments.

\section{Supplementary material}

4 files:

- Comparisons with literature data

- 3 Chemkin format files (mechanism, thermodynamic and transport properties)

\section{References}

[1] K.J. Morganti, T.M. Foong, M.J. Brear, G. da Silva, Y. Yang, F.L. Dryer, Fuel, 108 (2013), pp. 797-811

[2] C.K. Westbrook, W.J. Pitz, H.J. Curran, J. Phys. Chem. A, 110 (2006), pp. 6912-6922

[3] P. Dagaut, M. Cathonnet, J.C. Boettner, J. Phys. Chem., 92 (1988), pp. 661-671

[4] T. Le Cong, E. Bedjanian, P. Dagaut, Combust. Sci. Technol., 182 (2010), pp. 333-349

[5] S.G. Davis, C.K. Law, H. Wang, Combust. Flame, 119 (1999), pp. 375-399

[6] C.K. Westbrook, W.J. Pitz, Combust. Sci. Technol., 37 (1984), pp. 117-152

[7] R. Wilk, N. Cernansky, W. Pitz, C. Westbrook, Combust. Flame, 77 (1989), pp. 145-170

[8] T.R. Simonyan, A.A. Mantashyan, React. Kinet. Catal. L, 17 (1981), pp. 319-322

[9] W. Tsang, J. Phys. Chem. Ref. Data, 20 (1991), pp. 221-273

[10] S.M. Burke, U. Burke, R. Mc Donagh, O. Mathieu, I. Osorio, C. Keese, E.L. Peterson, W. Wang, M. Oehlschlaeger, B. Rhodes, R.K. Hanson, D. Davidson, B.W. Weber, C.J. Sung, J. Santner, Y. Ju, E. Volkov, A.A. Konnov, M. Alrefae, F. Khaled, A. Farooq, H.J. Curran. Combust. Flame, 2014 (submitted for publication).

[11] B. Heyberger, F. Battin-Leclerc, V. Warth, R. Fournet, G. Come, G. Scacchi, Combust. Flame, 126 (2001), pp. 17801802

[12] M. Braun-Unkhoff, N. Slavinskaya, M. Aigner, ASME Turbo Expo 2010: power for land Sea Air, 2 (GT2010-23360) (2010), pp. 1037-1047

[13] J. Warnatz, W.C. Gardiner (Ed.), Combustion Chemistry, Springer, US (1984), pp. 197-360

[14] R. Baldwin, R. Walker, Proc. Combust. Inst., 18 (1981), pp. 819-829

[15] P. Dagaut, M. Cathonnet, J.C. Boettner, Combust. Sci. Technol., 83 (4-6) (1992), pp. 167-185 
[16] D.L. Baulch, C.T. Bowman, C.J. Cobos, R.A. Cox, T. Just, J.A. Kerr, M.J. Pilling, D. Stocker, J. Troe, W. Tsang, R.W. Walker, J. Warnatz, J. Phys. Chem. Ref. Data, 34 (2005), pp. 757-1397

[17] Y. Hidaka, T. Nakamura, H. Tanaka, A. Jinno, H. Kawano, T. Higashihara, Int. J. Chem. Kinet., 24 (1992), pp. 761-780

[18] R. Fournet, J.C. Bauge, F. Battin-Leclerc, Int. J. Chem. Kinet., 31 (5) (1999), pp. 361-379

[19] CHEMKIN-PRO Release 15101, 2010, Reaction Design: San Diego.

[20] O. Herbinet, P.-M. Marquaire, F. Battin-Leclerc, R. Fournet, J. Anal. Appl. Pyrolysis, 78 (2007), pp. 419-429

[21] B. Husson, O. Herbinet, P.A. Glaude, S.S. Ahmed, F. Battin-Leclerc, J. Phys. Chem. A, 116 (2012), pp. 5100-5111

[22] R. David, D. Matras, Canadian J. Chem. Eng., 53 (1975), pp. 297-300

[23] J. Tranchant, J. Gardais, Manuel pratique de chromatographie en phase gazeuse, Masson (1982)

[24] NIST Standard Reference Database 1A, NIST/EPA/NIH Mass Spectral, National Institute of Standards and Technology, 2008.

[25] S.M. Sarathy, S. Vranckx, K. Yasunaga, M. Mehl, P. Oßwald, W.K. Metcalfe, C.K. Westbrook, W.J. Pitz, K. KohseHöinghaus, R.X. Fernandes, H.J. Curran, Combust. Flame, 159 (2012), pp. 2028-2055

[26] T.J. Held, F.L. Dryer, Int. J. Chem. Kinet., 30 (1998), pp. 805-830

[27] Z. Zhao, M. Chaos, A. Kazakov, F.L. Dryer, Int. J. Chem. Kinet., 40 (2008), pp. 1-18

[28] T.J. Held, F.L. Dryer, Proc. Combust. Inst., 25 (1994), pp. 901-908

[29] S. Dooley, M. Burke, M. Chaos, Y. Stein, F. Dryer, V. Zhukov, O. Finch, J. Simmie, H. Curran, Int. J. Chem. Kinet., 42 (2010), pp. 527-549

[30] F. Haas PhD thesis, Mechanical and Aerospace Engineering, Princeton University, 2014.

[31] A. Kéromnès, W.K. Metcalfe, K.A. Heufer, N. Donohoe, A.K. Das, C.-J. Sung, J. Herzler, C. Naumann, P. Griebel, O. Mathieu, M.C. Krejci, E.L. Petersen, W.J. Pitz, H.J. Curran, Combust. Flame, 160 (2013), pp. 995-1011

[32] W.K. Metcalfe, S.M. Burke, S.S. Ahmed, H.J. Curran, Int. J. Chem. Kinet., 45 (2013), pp. 638-675

[33] C.J. Aul, W.K. Metcalfe, S.M. Burke, H.J. Curran, E.L. Petersen, Combust. Flame, 160 (2013), pp. 1153-1167

[34] M.M. Kopp, E. L Petersen, W. K. Metcalfe, S. M. Burke, H. J. Curran, J. Propul. Power, 30 (2014), pp. 790-798

[35] Y. Kochar, J. Seitzman, T. Lieuwen, W.K. Metcalfe, S.M. Burke, H.J. Curran, M. Krejci, W. Lowry, E. Petersen, G. Bourque, In ASME Paper GT2011-45122, 56th ASME Turbo Expo, 2012.

[36] G. Mittal, S.M. Burke, V.A. Davies, B. Parajuli, W.K. Metcalfe, H.J. Curran, Combust. Flame (2013) http://dx.doi.org.bases-doc.univ-lorraine.fr/10.1016/j.combustflame.2013.11.005.

[37] D. Healy, N.S. Donato, C.J. Aul, E.L. Petersen, C.M. Zinner, Bourque, H.J. Curran, Combust. Flame, 157 (2010), pp. 1526-1539

[38] D. Healy, N. Donato, C. Aul, E.L. Petersen, C. Zinner, G. Bourque, H.J. Curran, Combust. Flame, 157 (2010), pp. 15401551

[39] D. Healy, M.M. Kopp, N.L. Polley, E.L. Petersen, G. Bourque, H.J. Curran, Energy Fuels, 24 (2010), pp. 1617-1627

[40] D. Healy, D.M. Kalitan, C.J. Aul, E.L. Petersen, G. Bourque, H.J. Curran, Energy Fuels, 24 (2010), pp. 1521-1528

[41] A. Laskin, H. Wang, C.K. Law, Int. J. Chem. Kinet., 32 (2000), pp. 589-614

[42] W.K. Metcalfe, S. Dooley, F.L. Dryer, Energy Fuels, 25 (2011), pp. 4915-4936 
[43] G. Jomaas, X.L. Zheng, D.L. Zhu, C.K. Law, Proc. Combust. Inst., 30 (2005), pp. 193-200

[44] H.J. Curran, Int. J. Chem. Kinet., 38 (2006), pp. 250-275

[45] J.A. Miller, S.J. Klippenstein, J. Phys. Chem. A, 117 (2013), pp. 2718-2727

[46] S.S. Vasu, Z. Hong, D.F. Davidson, R.K. Hanson, D.M. Golden, J. Phys. Chem. A, 114 (2010), pp. 11529-11537

[47] J. Zádor, A.W. Jasper, J.A. Miller, Phys. Chem. Chem. Phys., 11 (2009), pp. 11040-11053

[48] J. C Loison, J. Daranlot, A. Bergeat, F. Caralp, R. Mereau, K.M. Hickson, J. Phys. Chem. A, 114 (2010), pp. 13326-13336

[49] A. Frassoldati, A. Cuoci, T. Faravelli, U. Niemann, E. Ranzi, S. Reinhard, S. Kalyanasundaram, Combust. Flame (2010), pp. 2-16

[50] M. Scott, R.W. Walker, Combust. Flame, 129 (2002), pp. 365-377

[51] J. Zádor, S.J. Klippenstein, J.A. Miller, J. Phys. Chem. A, 115 (2011), pp. 10218-10225

[52] R. Baldwin, C.E. Dean, R.W. Walker, J. Chem. Soc. Faraday Trans., 82 (1986), pp. 1445-1455

[53] D.L. Baulch, C.J. Cobos, R.A. Cox, P. Frank, G. Hayman, T. Just, J.A. Kerr, T. Murrells, M.J. Pilling, J. Troe, R.W. Walker, J. Warnatz, J. Phys. Chem. Ref. Data, 23 (1994), pp. 847-848

[54] P. Barbé, F. Baronnet, R. Martin, D. Perrin, Int. J. Chem. Kinet., 30 (1998), pp. 503-522

[55] N.D. Stothard, R.W. Walker, J. Chem. Soc. Faraday Trans., 87 (1991), pp. 241-247

[56] C.F. Goldsmith, S.J. Klippenstein, W.H. Green, Proc. Combust. Inst., 33 (2011), pp. 273-282

[57] S. Rolland, J.M. Simmie, Int. J. Chem. Kinet., 37 (2005), pp. 119-125

[58] M.A. Oehlschlaeger, D.F. Davidson, R.K. Hanson, Combust. Flame, 147 (2006), pp. 195-208

[59] H.-H. Carstensen, A.M. Dean, J. Phys. Chem. A, 113 (2009), pp. 367-380

[60] J.D. Savee, O. Welz, C.A. Taatjes, D.L. Osborn, Phys. Chem. Chem. Phys., 14 (2012), pp. 10410-10423

[61] J.A. Miller, J.P. Senosiain, S.J. Klippenstein, Y. Georgievskii, J. Phys. Chem. A, 112 (2008), pp. 9429-9438

[62] A.Y. Chang, J.W. Bozzelli, A.M. Dean, Z. Phys, Chem., 214 (2000), pp. 1533-1568

[63] J.W. Bozzelli, A.M. Dean, J. Phys. Chem., 97 (1993), pp. 4427-4441

[64] S.J. Klippenstein, Y. Georgievskii, J.A. Miller, J.A. Nummela, B.K. Carpenter, P.R. Westmoreland, in: Proceedings of the Third Joint Meeting of the U. S. Sections of The Combustion Institute, 2003.

[65] P.T. Lynch, C.J. Annesley, C.J. Aul, X. Yang, R.S. Tranter, J. Phys. Chem. A, 117 (2013), pp. 4750-4761

[66] A. Fridlyand, P.T. Lynch, R.S. Tranter, K. Brezinsky, J. Phys. Chem. A, 117 (2013), pp. 4762-4776

[67] J.P. Orme, H.J. Curran, J.M. Simmie, J. Phys. Chem. A, 110 (2006), pp. 114-131

[68] W. Pitz, C. Naik, T.N. Mhaoldúin, C. Westbrook, H. Curran, J. Orme, J. Simmie, Proc. Combust. Inst., 31 (2007), pp. 267-275

[69] T. Ingham, R. Walker, R. Woolford, Proc. Combust. Inst., 25 (1994), pp. 767-774

[70] P. Dagaut, J.-C. Boettner, M. Cathonnet, Int. J. Chem. Kinet., 22 (1990), pp. 641-664

[71] S.G. Davis, C.K. Law, H. Wang, J. Phys. Chem. A, 103 (1999), pp. 5889-5899

[72] N. Hansen, J.A. Miller, P.R. Westmoreland, T. Kasper, K. Kohse-Höinghaus, J. Wang, T.A. Cool, Combust. Flame, 156 (2009), pp. 2153-2164 
[73] R. Atkinson, S.M. Aschmann, Int. J. Chem. Kinet., 16 (1984), pp. 259-268

[74] R. Atkinson, S.M. Aschmann, A. M Winer, J. N Pitts, Int. J. Chem. Kinet., 14 (1982), pp. 507-516

[75] C.F. Goldsmith, G.R. Magoon, W.H. Green, J. Phys. Chem. A, 116 (2012), pp. 9033-9057

[76] S.M. Burke PhD thesis, School of Chemistry, NUI Galway, 2013.

[77] Z. Qin, H. Yang, W.C. Gardiner, Combust. Flame, 124 (2001), pp. 246-254 